Volume 8 | Issue 2

2-11-2021

\title{
Giving Pharmacists Provider Rights
}

Tanya E. Karwaki

West Virginia University College of Law, tanya.karwaki@mail.wvu.edu

Follow this and additional works at: https://scholarship.law.tamu.edu/lawreview

Part of the Health Law and Policy Commons, Medical Sciences Commons, Pharmacy and Pharmaceutical Sciences Commons, and the Telemedicine Commons

\section{Recommended Citation}

Tanya E. Karwaki, Giving Pharmacists Provider Rights, 8 Tex. A\&M L. Rev. 331 (2021). Available at: https://doi.org/10.37419/LR.V8.I2.3

This Article is brought to you for free and open access by Texas A\&M Law Scholarship. It has been accepted for inclusion in Texas A\&M Law Review by an authorized editor of Texas A\&M Law Scholarship. For more information, please contact aretteen@law.tamu.edu. 


\title{
GIVING PHARMACISTS PROVIDER RIGHTS
}

\author{
by: Tanya E. Karwaki*
}

\begin{abstract}
Changes to our health care system, robotics and health care mergers among them, are forcing pharmacists into expanded provider roles, yet federal policymakers are failing to act on these changes. State lawmakers are acting but not swiftly enough. A federal response, including recognizing pharmacists as health care providers and making them eligible for independent Medicare reimbursement, will be necessary to enable pharmacists to fill their role in our health care system. Policymakers have an opportunity now to respond proactively to a changing climate in health care by clarifying the boundaries on pharmacists' services, particularly those boundaries regarding direct patient care and the appropriate reimbursement level. In doing so, policymakers may also alleviate some of the scope of practice "turf wars" health care providers engage in and incentivize better patient care and lower health care costs.
\end{abstract}

I. Introduction.............................. 332

II. Pharmacist Provider Status and the American Health Care System ..........................

A. What Is Provider Status?................... 334

B. The Likely Effects of Federal Pharmacist Provider Status on the American Health Care System........ 338

1. Improving Health Care Outcomes ........... 339

2. Improving Interdisciplinary Health Care Teams................................

3. Contributing to Health Care Cost Savings ......

III. The Federal Pharmacist Provider Status Tipping Point ......................................

A. Robots and Automation in Pharmacies............ 343

B. Pharmacy Mergers and Acquisitions ............. 345

C. Transitioning to Value-Based Care ............... 348

D. Advanced Pharmacy Technicians ............... 350

IV. Learning from State and Federal Efforts to Establish Pharmacist Provider Status ............

A. State Pharmacist Provider Status Legislation: A Spotlight on the West Coast States' Provider Status Legislation ................................. 351

B. Federal Pharmacist Provider Status ............. 354 1. Legislating Federal Pharmacist Provider Status . 354 2. Federal Administrative Agency Rulemaking.... 356

DOI: https://doi.org/10.37419/LR.V8.I2.3

* Health Law Fellow, West Virginia University College of Law. Thanks to Valarie Blake for her helpful comments and encouragement and to Jennifer Wilson Norton for her cheerful willingness to discuss pharmacy practice with a lawyer. 
V. Preparing for a Federal Solution to Pharmacist Provider Status ...............................

A. Who Can Perform What Services Where? .......... 358

B. Placing Boundaries on Pharmacists' Direct Patient Care ........................................ 359

C. Resolving Reimbursement ................... 361

D. Existing Barriers to a Federal Solution ............ 362

VI. Conclusion ................................... 366

\section{INTRODUCTION}

Many patients picking up a prescription from a drive-through pharmacy on their commute home may consider the pharmacist as more of a vendor than a health care provider, if they think of the pharmacist at all. To these patients, pharmacists appear confined to a lick, stick, count, and pour role. ${ }^{1}$ However, today's pharmacists can also serve as health care providers, giving the flu vaccine and other vaccines, ${ }^{2}$ prescribing over-the-counter-nicotine-replacement patches and other products, ${ }^{3}$ and rounding with hospital health care teams to provide real-time advice about pharmaceutical therapies. ${ }^{4}$ This shift represents a relatively recent change in pharmacists' role in our health care system from one of primarily selling drugs ${ }^{5}$ to providing more direct patient care. Indeed, pharmacists may improve patient care and decrease health care costs, improvements our health care system needs with over $\$ 528$ billion in drug-related morbidity and mortality costs in one year. ${ }^{6}$ At the same time pharmacy practice is changing, significant health care system changes are also occurring, impacting pharmacists and other health care providers. Combined, these changes illustrate a growing gap between pharmacists' provider role and the law's failure

1. See generally Terence C. Green, Licking, Sticking, Counting, and Pouring - Is That All Pharmacists Do? McKee v. American Home Products Corp., 24 Creighton L. ReV. 1449, 1476 (1991).

2. Joan Vos MacDonald, State Laws and Vaccination Services, 163 DRUG TopICs 1, 18 (Dec. 2019), https://cdn.sanity.io/files/0vv8moc6/drugtopics/6cab 5bcc64db1ff15d3a17f19ef75a4092fb0b01.pdf [https://perma.cc/CJZ4-DNLD] (providing an overview of additional ways states regulate pharmacist-administered vaccines).

3. See Cal. Bus. \& Prof. Code $\S 4052$ (a)(10) (West 2018).

4. See Gallegos v. Wood, No. CIV 13-1055, No. CIV 15-0184, 2016 WL 1426554, at *1 (D.N.M. Mar. 31, 2016). Veterans Affairs and the Indian Health Service differ from Medicare in recognizing pharmacists as providers. CMS Response Misses Point of Provider Status, Am. Pharmacists Ass'N (Jan. 28, 2014), https:// www.pharmacist.com/CEOBlog/cms-response-misses-point-provider-status [https:// perma.cc/R6QH-63QF].

5. See David B. Brushwood, The Pharmacist's Duty to Warn: Toward a Knowledge-Based Model of Professional Responsibility, 40 Drake L. REv. 1, 3 (1991) (describing one of a pharmacist's many identities as that of a retail merchant).

6. Jonathan H. Watanabe, Terry McInnis \& Jan D. Hirsch, Cost of Prescription Drug-Related Morbidity and Mortality, 52 Annals Pharmacotherapy 829, 829 (2018). 
to regulate them accordingly. Now is the time for federal legislators and policymakers to proactively construct a federal solution giving pharmacists provider rights within the context of broad changes to our health care landscape.

Pharmacists seek provider status at the state and federal levels to qualify for appropriate reimbursement for their services. Without provider status, pharmacists cannot be directly paid for many of the patient care services they are qualified to provide, as evidenced by pharmacists' inability to independently bill Medicare.

While federal pharmacist provider status may eventually be established due to state lawmakers' efforts to create a similar status at the state level, this Article argues that changes in the health care system are tipping towards dramatic, fast-paced change-one that will require regulation. Part II examines pharmacist provider status in the context of the American health care system. Part III asserts that changes in our health care landscape, including the increased use of robots and automation in pharmacy practice and Amazon's foray into pharmacy, create a tipping point toward federal pharmacist provider status. Part IV analyzes state statutes and federal efforts for how they can inform future federal law. Finally, Part V highlights key issues and possible solutions federal policymakers should consider in regulating federal pharmacist provider status.

\section{Pharmacist Provider Status and the American Health CARE System}

Many aspects of our existing health care system may be improved if pharmacists have provider status. Patients may gain increased access to pharmacist-provided health care services, which are often closer to home $^{7}$ and available outside traditional primary care clinic hours. Pharmacist provider status may also help reduce costs in the health care system, with lower charges to the patients or their insurance companies compared with physician-provided services. Moreover, improved access to pharmaceutical care may save money on future health care services ${ }^{8}$ by preventing or reducing further degree progression and development of comorbid conditions. ${ }^{9}$ Provider status

7. Approximately $93 \%$ of Americans live five miles or less from a pharmacy. Nat'l Ass'n Chain Drug Stores, 2010-2011 Chain Pharmacy Industry Profile Illustrates Pharmacy Value, DRUG TopICs (Sept. 21, 2010), https://www.drugtopics.com/topnews/nacds-2010-2011-chain-pharmacy-industry-profile-illustrates-pharmacy-value [https://perma.cc/J3ND-84ZJ].

8. The U.S. Public Health Service Chief Pharmacist reported to the U.S. Surgeon General that "for each dollar invested in the clinical pharmacy service . . . the overall average benefit gained was $\$ 10.07$ per $\$ 1$ of allocated funds." Scott Giberson, Sherri Yoder \& Michael P. Lee, Improving Patient and Health System Outcomes Through Advanced Pharmacy Practice: A Report to the U.S. Surgeon General 2011, U.S. Pub. Health Serv. 1, 41 (2011).

9. Id. at 39 . 
brings provider rights, so policymakers must determine the appropriate role for pharmacists before tailoring the solution to that role. With these goals in mind, this Part examines pharmacist provider status and its close connection to reimbursement and analyzes the foreseeable effects of federal pharmacist provider status on key aspects of our health care system, including health care outcomes and cost savings.

\section{A. What Is Provider Status?}

"Provider" is a term that policymakers, health care professionals, patients, legal scholars, health science scholars, private insurers, and other stakeholders often use when referring to various health care professionals. This term, however, has different meanings, so its usage can sometimes be confusing. The dictionary, ${ }^{10}$ patients, and even some legal scholars ${ }^{11}$ use the term provider generically to refer to health care professionals providing patient care.

The law, however, defines a provider differently depending on the context. For example, a health care professional might be a provider for purposes of malpractice liability ${ }^{12}$ but not for purposes of reimbursement. In each of these examples, the law expressly enumerates the type of health care professional, such as a physician or a pharmacist, who is legally a provider in a particular context. In doing so, the law delineates who is and is not a provider; any accompanying benefits or obligations of being a provider attach only to those satisfying the provider definition.

10. Merriam Webster defines a "provider" as one who provides, such as a health care provider. Provider, MERriam-Webster, https://www.merriam-webster.com/dictionary/provider?utm_campaign=sd\&utm_medium $=$ serp\&utm_source=jsonld [https:// perma.cc/TV2U-8YJ8].

11. See William L. Allen \& David B. Brushwood, Pharmaceutically Assisted Death and the Pharmacist's Right of Conscience, 5 J. Pharmacy \& L. 1, 1 (1996) ("Pharmacists are health care providers who accept responsibility for the outcomes of drug therapy by accurately processing medication orders, detecting and rectifying potential problems with drug therapy, counseling patients concerning the anticipated effects of drugs, and monitoring the results of drug use."); David B. Brushwood, The Professional Capabilities and Legal Responsibilities of Pharmacists: Should "Can" Imply "Ought”?, 44 Drake L. REv. 439, 441 (1996) ("Among health care providers, pharmacists are uniquely qualified and situated to oversee the drug-use process."). This more generic use of "provider" is illustrated in many legal scholars' works addressing the issue of pharmacists' refusal to dispense emergency contraception based on personal beliefs. See, e.g., Holly Teliska, Obstacles to Access: How Pharmacist Refusal Clauses Undermine the Basic Health Care Needs of Rural and Low-Income Women, 20 Berkeley J. Gender L. \& Just. 229, 230 (2005) (discussing state bills permitting pharmacist providers to deny women access to contraception because of a pharmacist's beliefs); Maxine M. Harrington, The Ever-Expanding Health Care Conscience Clause: The Quest for Immunity in the Struggle Between Professional Duties and Moral Beliefs, 34 FLA. ST. U. L. REv. 779, 784-85 (2007) (referring to pharmacists as providers in addressing a provider's right to refuse care because of personal beliefs).

12. See, e.g., WAsh. Rev. Code Ann. § 7.70.020(1) (West 2020) (defining health care provider to include a pharmacist for purposes of health care malpractice claims). 
Generally, federal law is limited to defining who is or is not a provider for purposes of being eligible to apply for reimbursement from federal payers such as Medicare ${ }^{13}$ (which provides health insurance for disabled persons and persons sixty-five years of age or older).

At the federal level, achieving Medicare Part $\mathrm{B}^{14}$ reimbursement is crucial for non-physician practitioners. ${ }^{15}$ This is partly because of the large number of patients covered by Medicare. As of 2019, there were almost 61 million Medicare beneficiaries, with 10,000 new enrollees joining every day. ${ }^{16}$ By 2023 , it is estimated that more than 80 million Americans will qualify for Medicare. ${ }^{17}$ In addition to the large number of Medicare patients, another reason Medicare reimbursement is sought by health care professionals is that state and private insurers tend to follow the federal government's lead. ${ }^{18}$

Reimbursement, similar to other aspects of health care, is complicated. ${ }^{19}$ Two of the primary Medicare reimbursement methods available to non-physician providers are independently billing Medicare or billing Medicare incident-to a physician. If the non-physician provider's service is an integral part of the physician's service, then the non-physician provider's service may be billed to Medicare under the physician's name as an incident-to service. ${ }^{20}$ In this form of billing, because it is directly linked to the physician's care, the claim is paid at

13. 42 U.S.C. $\$ 1395-1395$ iii.

14. Medicare Part B covers outpatient services for elderly and disabled beneficiaries; Medicare Part A covers hospital, or inpatient, services. See Craig B. Garner, Medicare: The Perpetual Balance Between Performance and Preservation, 30 J. CoNTemp. Health L. \& Pol'y 279, 281-82 (2014) (providing a brief history of Medicare and the coverage provided by parts $\mathrm{A}$ and $\mathrm{B}$ ).

15. John S. Linehan, The Legal Implications of Pharmacist Provider Status and the Transformation of an Industry, 18 Am. Health L. Ass'N Connections 20, 21 (2014). Nurse practitioners are an example of a mid-level practitioner receiving "near-universal recognition under the state and private insurance programs after achieving provider status under Medicare Part B." Id. (citing John Michael O'Brien, How Nurse Practitioners Obtained Provider Status: Lessons for Pharmacists, 60 Aм. J. HealthSys. Pharmacists 2301, 2306 (2003)).

16. Seema Verma, The Future of Medicare Program Integrity, CTRs. FOR MEDICARE \& Medicaid Servs. (Oct. 21, 2019), https://www.cms.gov/blog/future-medicare-program-integrity [https://perma.cc/ATS9-FJUR].

17. Erica M. Tolle et al., A Survey of Pharmacists' Preparedness for Provider Status Implementation, 57 J. Am. Pharmacists Ass'N S284, S284 (2017).

18. Barbara J. Safriet, Health Care Dollars and Regulatory Sense: The Role of Advanced Practice Nursing, 9 Yale J. on Regul. 417, 468 (1992). For instance, once nurse practitioners achieved provider status under Medicare Part B, they also received broader recognition from state and private insurance programs. Linehan, supra note 15 , at 21 .

19. See Kevin Liptak, Trump: 'Nobody Knew Health Care Could Be So Complicated', CNN: PoL., https://www.cnn.com/2017/02/27/politics/trump-health-care-complicated/index.html (Feb. 28, 2017, 4:10 AM) [https://perma.cc/2KAE-9ZLZ].

20. Alice G. Gosfield, The Ins and Outs of "Incident-To" Reimbursement, 8 FAM. Prac. Mgmt. 23, 24 (2001) (thoroughly discussing the history and rules regarding incident-to billing). 
$100 \%$ of the physician fee schedule. ${ }^{21}$ Non-physician providers who independently bill Medicare are typically reimbursed by Medicare at $85 \%$ of physician reimbursement rates. ${ }^{22}$ This lower reimbursement rate accounts for the fact that a physician's services were not necessary, enabling the physician to care for a more clinically complex patient while reducing the health care system's costs. ${ }^{23}$ Regardless of how a non-physician ultimately bills Medicare, independently or incident-to, the service the provider is billing for must be within the provider's scope of practice ${ }^{24}$ or permitted by state statute.

For a health care professional to be eligible to seek reimbursement from Medicare Part B, the health care professional must be defined as a provider in section 1861 of the Social Security Act. ${ }^{25}$ Currently, physicians, nurse practitioners, and physician assistants are included in the list of providers, but pharmacists are not. ${ }^{26}$ Since pharmacists are not providers ${ }^{27}$ under section 1861 of the Social Security Act, ${ }^{28}$ they are unable to bill Medicare for their pharmacist services, unlike the recognized providers. ${ }^{29}$ Nurse practitioners' and physician assistants' ability to bill for services ${ }^{30}$ is one reason they outnumber pharmacists in outpatient settings. ${ }^{31}$

Unlike in 1965 when Medicare was created, ${ }^{32}$ pharmacists in 2020 do more than lick, stick, count, and pour. ${ }^{33}$ Yet pharmacists are still reimbursed according to the historical dispensing model, where pharmacists were primarily drug sellers paid for the drugs plus a dispensing

21. Id. at 23 .

22. Id. at 26 .

23. Clay C. Johnson, A Case for an Efficient System: How Relaxing Midlevel Provider Supervision and Prescriptive Authority Laws Will Reduce Costs and Increase Access to Health Care in Alabama, 45 Cumb. L. Rev. 565, 593 (2015).

24. See Georgette Gustin, Allied Health Professionals Should Provide Only Those Services That Are Within Their Scope of Practice, 9 J. Health Care Compliance 23, 63 (2007) (explaining the importance of allied health professionals, such as nurse practitioners and physician assistants, billing for services within their scopes of practice).

25. Social Security Act $\S 1861,42$ U.S.C. $\S 1395(k)(a)(2)(B),(x)(s)$.

26. Social Security Act $\S 1861,42$ U.S.C. $\S 1395(x)(s)$.

27. Johanna L. Keely, Pharmacist Scope of Practice, 136 Annals Internal Med. 79,83 (2002) (" $[\mathrm{P}]$ harmacists are not approved providers under Medicare except to perform immunizations ....").

28. 42 U.S.C. $\S 1395(\mathrm{x})(\mathrm{s})$.

29. Scott J. Knoer, Allison R. Eck \& Amber J. Lucas, A Review of American Pharmacy: Education, Training, Technology, and Practice, 2 J. Pharm. Health CARE \& ScIs. 32, 37 (2016).

30. See Johnson, supra note 23 , at 571-72 (providing an overview of insurance reimbursement for mid-level providers).

31. Knoer, Eck \& Lucas, supra note 29, at 36.

32. See Social Security Amendments of 1965, Pub. L. No. 89-97, § 102(a), 77 Stat. 275 (codified as amended at 42 U.S.C. $\S 1395$ ).

33. See Green, supra note 1 , at 1476 . 
fee. ${ }^{34}$ Pharmacists' reimbursement has not kept pace with their expanding skills and contributions to the health care system.

To be clear, pharmacists currently provide some direct patient care, although they are not often reimbursed for the actual level of service provided to patients. ${ }^{35}$ For example, anticoagulation-ambulatory-care clinics have been successful settings for pharmacists and are usually welcomed by physicians ${ }^{36}$ since the pharmacists relieve the physicians' burden of monitoring and adjusting anticoagulation medicines. ${ }^{37}$ Pharmacists in these clinics educate patients, order laboratory tests, and adjust medications as needed. ${ }^{38}$ These pharmacists are not rogue, acting entirely on their own. Rather, they collaborate closely with physicians, establishing a collaborative practice agreement and regularly communicating with the physicians and other prescribers. ${ }^{39} \mathrm{Al}$ though the pharmacists' patient care provided in an anticoagulation clinic may decrease the number of patient visits to the emergency department and the frequency of patient admissions to the hospital, ${ }^{40}$ Medicare's failure to reimburse pharmacist services means that such clinics must find alternative funding mechanisms rather than simply billing Medicare directly for the pharmacists' care. Alternatively, many accountable care organizations and other health care organizations may exclude pharmacists because pharmacists are unable to be reimbursed for most Medicare services. ${ }^{41}$ While many hospitals allocate other available funds to cover the pharmacist costs of operating an anticoagulation clinic, these clinics are unsustainable in the long term without pharmacist independent billing. ${ }^{42}$

34. Terri V. Newman et al., Optimizing the Role of Community Pharmacists in Managing the Health of Populations: Barriers, Facilitators, and Policy Recommendations, 25 J. Managed Care \& Specialty Pharmacy 995, 996 (2019).

35. See Keely, supra note 27 , at $80-81$ (discussing pharmacists' role in drug therapy programs, intensive care units, and local clinics).

36. Donna Young, Medicare Compensation Would Open Pharmacist-Managed Service to More Patients, 59 Am. J. Health-Sys. Pharmacy 811, 812 (2002).

37. Other examples of possible pharmacy-managed programs include asthma and diabetes management. See, e.g., Terri V. Newman et al., Impact of Community Pharmacist-Led Interventions in Chronic Disease Management on Clinical, Utilization, and Economic Outcomes: An Umbrella Review, 16 Rsch. Soc. \& Admin. Pharmacy 1155, 1156 (2020).

38. See Keely, supra note 27 , at $80-81$.

39. See id.

40. Young, supra note 36, at 811.

41. Lisa English Hinkle, Pharmacists: Aren't You Really Providers Already? - Part One, NAT'L L. REV. (Apr. 21, 2015), https://www.natlawreview.com/article/pharmacists-aren-t-you-really-providers-already-part-one [https://perma.cc/V8PN-HEKK].

42. Medicare compensation would open pharmacist-managed services to more patients. Young, supra note 36, at 811 (describing Shore Health Systems of Maryland initiating and operating its anticoagulation clinic using funds from the hospital foundation). 
Since state law governs the licensure of health care professionals, ${ }^{43}$ most of the legal definitions of a provider are found in state law and thus differ from state to state. In some states, such as California ${ }^{44}$ and Ohio, ${ }^{45}$ the legislature deems pharmacists as health care providers with the authority to perform health care services. By including pharmacists on the list of health care providers, state legislatures may give pharmacists greater recognition, perhaps increasing their professional stature and encouraging pharmacists' further contributions to patient health care. Legislative declarations of pharmacist provider status alone, however, do not govern another critical component of provider status: payment for services rendered. If pharmacists, as health care providers, are to be reimbursed for services from payers, the legislature must mandate coverage ${ }^{46}$ or establish discretionary coverage. ${ }^{47}$ Eligibility for reimbursement is critical to incentivizing any health care professional to provide patient care to the fullest extent possible.

For purposes of this Article, state pharmacist provider status refers to the status that state legislatures establish for pharmacists, while federal pharmacist provider status refers to a status created by federal law, either a statute or administrative rule, that enables pharmacists to seek reimbursement from Medicare for health care services. Only federal law, not state law, can establish Medicare reimbursement for a provider. Having federal pharmacist provider status may increase the likelihood of reimbursement from Medicaid and private insurers, as these payers often follow Medicare's lead regarding the types of health care professionals deemed to be providers for reimbursement purposes.

\section{B. The Likely Effects of Federal Pharmacist Provider Status on the American Health Care System}

Improving health care outcomes, strengthening interdisciplinary health care teams, and contributing to health care cost savings are all likely-and intertwined-impacts of federal pharmacist provider status on the health care system.

43. See Gabriel Scheffler, Unlocking Access to Health Care: A Federalist Approach to Reforming Occupational Licensing, 29 Health Matrix 293, 304-12 (2019) (providing a history of state health care professionals' licensure and its impact on access to health care).

44. Cal. Bus. \& Prof. Code $\S 4050$ (West 2020).

45. Ohio Rev. Code Ann. § 1751.01(Y) (West 2019-2020).

46. See Wash. Rev. Code AnN. \$ 48.43.094 (West Supp. 2019) (requiring reimbursement by most private insurers for specific pharmacist performed health care services).

47. See Or. Rev. Stat. § 414.764 (2017) (permitting reimbursement for pharmacist services from the Oregon Health Authority). 


\section{Improving Health Care Outcomes}

When we think of patient health care outcomes, individual patients and their good or bad health outcomes may come to mind first. While these are important, particularly to the individual patient, the health care system is also concerned with improving population health outcomes. Federal legislation, including the Patient Protection and Affordable Care Act ("PPACA") 48 and the Health Information Technology for Economic and Clinical Health ("HITECH") Act (promoting adoption of electronic health records and transfer of individual health information to public health agencies that can use data to assess population health), ${ }^{49}$ has encouraged the development and use of population-level outcome metrics. ${ }^{50}$ Pharmacists may provide services promoting both components of health care outcomes: individual patient health care outcomes and population health care outcomes.

While a limited number of pharmacists may already contribute to improving health care outcomes, ${ }^{51}$ federal pharmacist provider status will enable more pharmacists to do so. For instance, one area where pharmacists may improve health care outcomes is using their medication expertise in optimizing medication-related patient outcomes. ${ }^{52}$ Pharmacists may do this by reducing a patient's potential adverse drug events or by motivating patients to adhere to their medication therapy. Additionally, several health sciences studies suggest that pharmacists can improve patient outcomes with respect to diseases and conditions. ${ }^{53}$ Notably, researchers analyzing the impact of community pharmacy interventions on chronic disease management found that community pharmacists can improve clinical outcomes in chronic dis-

48. Patient Protection and Affordable Care Act, Pub. L. No. 111-148, 124 Stat. 119 (2010). See Barry R. Furrow, Regulating Patient Safety: The Patient Protection and Affordable Care Act, 159 U. PA. L. REv. 1727, 1737 (2011) (providing an overview of the PPACA's strategy for improving patient health outcomes and population health).

49. Health Information Technology for Economic and Clinical Health Act, Pub. L. No. 111-5, § 13407, 123 Stat. 226, 269-71 (2009).

50. Efthimios Parasidis, Health Outcomes Metrics and the Role of Financial Derivative Instruments in the Health Care Industry, 10 Ind. Health L. REv. 447, 450-59 (2013) (providing an overview of population health outcomes metrics).

51. See Jessica L. Van Beek, The Future for Pharmacists: Does Physician-Pharmacist Collaborative Practice Mean Collaborative Liability?, 36 J. Legal Med. 442, 444-46, 458 (2015) (analyzing pharmacist participation in patient care through the use of collaborative practice agreements between pharmacists and physicians).

52. Paul Denvir \& Jeffrey Brewer, "How Dare You Question What I Use to Treat This Patient?": Student Pharmacists' Reflections on the Challenges of Communicating Recommendations to Physicians in Interdisciplinary Health Care Settings, 30 Health Commc'N 504, 505 (2015).

53. But see Margaret McConnell et al., Architecting Process of Care: A Randomized Controlled Study Evaluating the Impact of Providing Nonadherence Information and Pharmacist Assistance to Physicians, 55 Health Servs. Rsch. 136, 136-37, 144 (2020) (analyzing results of a pilot study finding that pharmacists' phone calls to patients to help physicians address medication adherence did not improve adherence outcomes). 
eases including diabetes, HIV/AIDS, and cardiovascular and respiratory diseases. ${ }^{54}$ Chronic diseases are frequent drivers of morbidity and mortality as well as high health care costs. ${ }^{55}$

\section{Improving Interdisciplinary Health Care Teams}

The purpose of interdisciplinary health care teams is to combine the knowledge and skills of individual health care providers to provide an improved patient care experience. ${ }^{56}$ Ever since the Institute of Medicine's report entitled Health Professions Education: A Bridge to Quality ${ }^{57}$ recommending that "[a]11 health professionals should be educated to deliver patient-centered care as members of an interdisciplinary team," 58 such teamwork has been increasingly emphasized by the medical ${ }^{59}$ and other health care professions ${ }^{60}{ }^{\text {including pharmacy. }}{ }^{61}$ Some pharmacists have experience being part of an interdisciplinary health care team pursuant to a collaborative practice agreement ("CPA"), ${ }^{62}$ but lack of provider status and the associated eligibility for

54. Newman et al., supra note 37, at 1155, 1165 (noting that part of this study's significance is that for pharmacists to successfully transition from dispensing drugs to providing clinical care, they will need to demonstrate the impact of their clinical interventions on patients' outcomes).

55. Diabetes, heart disease, hypertension, asthma, and mental health are chronic health conditions accounting for about $80 \%$ of America's $\$ 3.5$ trillion annual health care expenditures. Nathaniel Meyersohn, This Is the CVS of the Future, CNN Bus., https://www.cnn.com/2019/02/16/business/cvs-health-healthhub-minuteclinic-aetna/index.html (Feb. 16, 2019, 7:21 AM) [https://perma.cc/S33D-P3FY].

56. Denvir \& Brewer, supra note 52, at 505.

57. Comm. on the Health Pros. Educ. Summit, Inst. of Med. of the Nat'L Acads., Health Professions Education: A Bridge to Quality 45-46 (Ann C. Greiner \& Elisa Knebel eds., 2003) (explaining that interdisciplinary teamwork is one of five core health professional competencies (The others are providing patient-centered care, employing evidence-based practice, applying quality improvement, and using information technology.)).

58. Id. at 121.

59. Linda Morton, Howard Taras \& Vivian Reznik, Teaching Interdisciplinary Collaboration: Theory, Practice, and Assessment, 13 Quinnipiac Health L.J. 175, 180-82 (2010) (providing the history of interdisciplinary collaboration within the medical profession).

60. See Rosaly Correa-de-Araujo, Evidence-Based Practice in the United States: Challenges, Progress, and Future Directions, 37 Health Care for Women Int'L 2, 3 (2016) (addressing nurses' involvement in health care teams and the implications for patient outcomes).

61. See K. L. Carter et al., Improved Latent Tuberculosis Therapy Completion Rates in Refugee Patients Through Use of a Clinical Pharmacist, 21 INT'L J. TuBERCULOSIS \& LuNG DisEASE 432, 432 (2017) (suggesting incorporating clinical pharmacists into interdisciplinary health care teams enhances patients' medication adherence and improves public health outcomes).

62. See generally Nat'l All. State Pharmacy Ass'ns et al., Advancing Team-Based Care Through Collaborative Practice Agreements: A Resource and Implementation Guide for Adding Pharmacists to the Care Team, Ctrs. For Disease Control \& PREVENTION (2017), https://www.cdc.gov/dhdsp/pubs/docs/cpa-team-based-care.pdf [https://perma.cc/RYZ3-2FFP] (thoroughly discussing the legal ramifications of CPAs in all states). Under CPAs, physicians and other health care professionals, including advanced practice nurses and physician assistants, may delegate some of their author- 
reimbursement prevent widespread inclusion of pharmacists as members of interdisciplinary teams. Federal pharmacist provider status can improve interdisciplinary teams because the addition of a pharmacist to the team brings enhanced medication knowledge.

\section{Contributing to Health Care Cost Savings}

In January 2018, Amazon, Berkshire Hathaway, and JPMorgan Chase \& Co. founded an independent company focusing on providing U.S. employees with quality, cost-effective health care. ${ }^{63}$ Media coverage of this announcement initially generated excitement in the health care industry. ${ }^{64}$ While any impact of this new venture remains to be seen, ${ }^{65}$ it does highlight how much the United States, including its businesses, is eager for high-quality, low-cost health care.

A recent research study estimates that there were approximately $\$ 528.4$ billion in drug-related-morbidity-and-mortality costs in one year in the United States. ${ }^{66}$ These costs include the direct medical costs associated with requiring additional medications and needing to access additional care by visiting a physician's office, a hospital, or an emergency department. ${ }^{67}$ Pharmacists, as medication experts, should be able to assist in decreasing these costs by improving patient adher-

ity to pharmacists. See id. at 8 (noting that almost all states permit some level of pharmacist-collaborative-practice authority, although not all states permit delegation of a prescriber's authority via a CPA); Linehan, supra note 15, at 24. For instance, in a Texas clinical practice group, pharmacists collaborate with physicians and advanced practice nurses to provide chronic care management of diseases such as asthma, diabetes, and hypertension. Wei C. Yuet et al., Pharmacist-Led Chronic Care Management Services, 17 Annals Fam. Med. 465, 465 (2019) (highlighting that significant time and resources were invested to build processes facilitating revenue-cycle management). At a North Carolina community teaching hospital, an interdisciplinary team, including a pharmacist, community paramedics, cardiology nurse practitioners, and physician assistants, works together to transition patients from the hospital to the patients' homes. Amanda Boykin et al., Interprofessional Care Collaboration for Patients with Heart Failure, 75 Am. J. Health-Sys. Pharmacy e45, e46 (2018).

63. Nicolas P. Terry, "Prime Health" and the Regulation of Hybrid Healthcare, 8 N.Y.U. J. InTell. Prop. \& ENT. L. 42, 43-45 (2018) (providing a framework for better understanding the roles of large technology companies in health care). Six months later, the threesome announced that Dr. Atul Gawande would lead the company. Id. at 58. One year later, the company announced its new name, Haven. John Tozzi, Amazon-JPMorgan-Berkshire Health-Care Venture To Be Called Haven, Bloomberg (Mar. 6, 2019, 3:05 PM), https://www.bloomberg.com/news/articles/2019-03-06/amazon-jpmorgan-berkshire-health-care-venture-to-be-called-haven [https://perma.cc/ 58EH-689G]. As this Article was going to press, Haven announced it will cease operating at the end of February 2021. Emily Flitter \& Karen Weise, Bold Health Care Venture Comes to a Quiet Ending, N.Y. Times, Jan. 5, 2021, at B1.

64. Tozzi, supra note 63.

65. Haven does have a website, containing limited information about its vision for health care. Vision, HAVEN, https://havenhealthcare.com/vision [https://perma.cc/ 6QMQ-A8SF].

66. Watanabe, McInnis \& Hirsch, supra note 6, at 832.

67. Id. (noting that these are direct medical costs and do not include direct nonmedical costs such as transportation or caregiving costs). 
ence to medication therapies and helping avoid a patient's need for additional treatment.

As our health care system focuses on cost-effective care, there is a growing expectation that health care providers and health care facilities can demonstrate their contributions toward lowering health care costs $^{68}$ and improving population health outcomes. ${ }^{69}$ Demonstrating this, however, is difficult for pharmacists because they lack provider status. $^{70}$ Without provider status, pharmacists cannot bill independently for their services, and so existing administrative and medical claims data, which typically capture the pharmacists' contribution under the prescribers' claims ${ }^{71}$ do not adequately reflect pharmacistprovided patient services. ${ }^{72}$ Not only does the data not reflect pharmacists' contributions to patient care, but more significantly, absent reimbursement, pharmacists lack incentives to provide patient care services. In turn, this deprives the health care system and patients of opportunities for improved patient care and lower health care costs.

Research studies indicate projected "cost savings of pharmacist-provided direct patient care services,"73 but additional data are necessary to better understand pharmacists' ability to reduce health care costs. One growing area where pharmacists may benefit patients and reduce health care costs is geriatric pharmacy. Older Americans often stockpile prescription medications, including those that are outdated, no longer needed, or potentially cause harm, ${ }^{74}$ which pharmacists can help evaluate and likely tailor to patient need.

Federal pharmacist provider status, with its ability for pharmacists to independently bill Medicare, will facilitate pharmacists' ability to conclusively demonstrate what seems likely_that pharmacists can indeed help the U.S. health care system realize cost savings.

68. See Knoer, Eck \& Lucas, supra note 29, at 32.

69. Newman et al., supra note 34, at 995.

70. For this reason, pharmacists consider validating their value beyond prescription dispensing to be one of the largest challenges for the pharmacy profession. Jenna Pizzi, Industry Analysis: Preparing for the Future of Healthcare and Pharmacy, USCIENCES (Apr. 16, 2019), https://www.usciences.edu/news/2019/industry-analysis-preparing-for-the-future-of-healthcare-and-pharmacy.html [https://perma.cc/2VR8$\mathrm{CXHJ}$.

71. See Elaine Nguyen \& John T. Holmes, Commentary, Pharmacist-Provided Services: Barriers to Demonstrating Value, 59 J. Am. Pharmacists Ass'n 117, 118 (2019) (demonstrating a cycle where pharmacists' lack of ability to bill independently for clinical services perpetuates barriers to demonstrating the value of pharmacists' clinical services).

72. See id.

73. Patrick C. Harper, Commentary, Pharmacist Provider Status Legislation: Projections and Prospects, 55 J. Am. Pharmacists Ass'n 203, 206 (2015).

74. See Aaron E. Carroll, The Unsung Role of the Pharmacist in Patient Health, N.Y. Times (Jan. 28, 2019), https://www.nytimes.com/2019/01/28/upshot/pharmacistsdrugs-health-unsung-role.html [https://perma.cc/WR5B-UD9R] (noting that "66 percent [of older adults] take five drugs or more per day, and 27 percent take 10 or more per day"). 


\section{The Federal Pharmacist Provider Status Tipping Point}

Malcolm Gladwell, in his bestselling book, The Tipping Point: How Little Things Can Make a Big Difference, ${ }^{75}$ described how something considered "outside the norm" can rapidly be normalized once a tipping point is reached. ${ }^{76}$ Gladwell explores social epidemics such as sweeping fashion trends, ${ }^{77}$ changing crime waves, ${ }^{78}$ and the rise of teenage smoking ${ }^{79}$ by comparing them to viral epidemics. ${ }^{80}$ Both viral and social epidemics are a function of transmission and the environment. ${ }^{81}$ Social epidemics tip when at least one "change agent" 82 catalyzes a social virus, causing it to move from equilibrium to an epidemic. ${ }^{83}$ Essentially, Gladwell believed that social epidemics take place when there is "the right messenger with the right message in the right social context." 84 Using Gladwell's framework, this Part asserts that automation, mergers, transitions to value-based care, and advanced pharmacy technicians are "little things" 85 that, combined, may form the right context for change. ${ }^{86}$ Moreover, these changes to the health care landscape may help modify the message from one of the providers fighting over scope of practice and reimbursement to one of improving patient care by better utilizing pharmacists in direct patient care.

\section{A. Robots and Automation in Pharmacies}

Similar to technological changes impacting our day-to-day lives, with ride shares such as Uber and Lyft changing how we move about and Amazon Fresh and other online grocery delivery services changing how we shop for our food, technological advancements also change components of our health care system. For instance, Uber permits health care providers to book rides for patients, and these rides

75. Malcolm Gladwell, The Tipping Point: How Little Things Can Make A Big Difference (1st ed., 2000).

76. Id. at 7-9, 13-14.

77. See id. at 3-5.

78. See id. at $133-68$.

79. See id. at $216-52$.

80. See id. at $15-29$.

81. Id. at 18.

82. Id. at $18-19$.

83. See id.

84. Jackie Gardina, The Tipping Point: Legal Epidemics, Constitutional Doctrine, and the Defense of Marriage Act, 34 VT. L. Rev. 291, 292 (2009).

85. GLADWELL, supra note 75 , at 150 .

86. See id. at 172 . 
are reimbursed by health insurers. ${ }^{87}$ Robots now assist in surgeries ${ }^{88}$ and also provide bedside care. ${ }^{89}$

Technological advances are also changing parts of pharmacy practice..$^{90}$ Pharmacy dispensing, once associated with mortars and pestles for compounding medication, is one area of pharmacy practice that is becoming increasingly automated..$^{91}$ For example, pharmacies utilize barcodes (like the ones in grocery stores) to improve patient safety by reducing human error. ${ }^{92}$ Barcodes enable pharmacists to more accurately track inventory, ${ }^{93}$ prepare patient doses, and appropriately dispense and administer prescriptions. ${ }^{94}$ Computers have been used extensively in pharmacy practice since the mid-1990s to assist pharmacists screening for drug-drug interactions, ${ }^{95}$ providing patient drug information, ${ }^{96}$ evaluating patient dosage ranges, ${ }^{97}$ and screening for patient drug allergies. ${ }^{98}$ More recently, computers and robots now drive the automated filling and dispensing machinery used by some hospitals and large pharmacies. ${ }^{99}$

Widespread automation in pharmacies may benefit our health care system, patients, and pharmacists. ${ }^{100}$ Increasingly, pharmacists are

87. Carolyn Said, Lyft, Uber See Gold in Business Market, S.F. Chron., Feb. 16, 2020 , at 2 .

88. Drew Simshaw et al., Regulating Healthcare Robots: Maximizing Opportunities While Minimizing Risks, 22 Rich. J.L. \& TECH. 1, 1 (2016).

89. Valarie K. Blake, Regulating Care Robots, 92 TemP. L. Rev. 551, 551 (2020).

90. See Marc R. Summerfield et al., Use of Pharmacy Delivery Robots in Intensive Care Units, 68 Am. J. Health-Sys. Pharmacy 77, 82 (2011) (evaluating a robotic delivery system for medications at the University of Maryland Medical Center and suggesting that "robots ... have contributed to the pharmacy's image of being technologically savvy . . ..”); Knoer, Eck \& Lucas, supra note 29, at 34.

91. Knoer, Eck \& Lucas, supra note 29, at 34.

92. Id.

93. See Justin D. Evans, Improving the Transparency of the Pharmaceutical Supply Chain Through the Adoption of Quick Response (QR) Code, Internet of Things (IoT), and Blockchain Technology: One Result: Ending the Opioid Crisis, 19 PITt. J. TeCH. L. \& PoL'y 35, 53 (2019) (proposing the use of quick response code, the internet of things, and blockchain technology to build off of bar code technology and further integrate prescription medication tracking to reduce the unwitting use of counterfeit medications).

94. Knoer, Eck \& Lucas, supra note 29, at 34.

95. Gary G. Cacciatore, Computers, OBRA 90 and the Pharmacist's Duty to Warn, 5 J. PhARMACY \& L. 103, 112 (1995) (exploring potential pharmacist liability arising from negligent use of a computer or failure to use a computer while practicing pharmacy).

96. See Husam Dauod et al., Robust Receding Horizon Control Strategy for Replenishment Planning of Pharmacy Robotic Dispensing Systems, 59 RовотіCs \& ComPUt.-InTEgRATEd MFg. 177, 177 (2019).

97. Elisabeth Belmont \& Adele A. Waller, The Role of Information Technology in Reducing Medical Errors, 36 J. Health L. 615, 616 (2003).

98. Summerfield et al., supra note 90, at 77.

99. Fred Gebhart, The Future of Pharmacy Automation, Drug Topics (July 4, 2019), https://www.drugtopics.com/automation/future-pharmacy-automation [https:// perma.cc/38DJ-NDK7].

100. $I d$. 
voicing their concerns ${ }^{101}$ that complying with corporate policies and performance metrics is leading to prescription errors that pose risks to patient safety. ${ }^{102}$ These concerns are not new; news media have covered similar incidents for over a decade. ${ }^{103}$ The foreseeable benefits of automated prescription filling include saving additional health care costs associated with patients receiving and taking incorrect prescription medications, improving patient care by avoiding potential adverse health events to patients, and facilitating better workplace environments for pharmacists.

In addition to automation, robots are being used more in health care, ${ }^{104}$ including in pharmacies. Pharmacies use robots primarily for tasks related to preparation and delivery of prescription medications. ${ }^{105}$ For instance, robots used to prepare toxic chemotherapy medications can improve pharmacists' safety by decreasing exposure to the toxic drugs from "spills, aerosol exposure, and needle sticks."106 And robots used to prepare and deliver prescription medications to intensive care units also decrease the time from prescription ordering to ultimate drug delivery to the patient. ${ }^{107}$ Automation, robots, and other technological advances may enable pharmacists to have more time for direct patient care, but pharmacists are unlikely to accept this new role and its associated responsibilities without federal pharmacist provider status.

\section{B. Pharmacy Mergers and Acquisitions}

Through mergers, the various components of our health care system, such as hospitals, insurers, and pharmacies, may achieve economies of scale and scope, which increases their ability to compete in the

101. See Ellen Gabler, At Walgreens, Complaints of Medication Errors Go Missing, N.Y. Times, Feb. 21, 2020, at A1 (reporting pharmacists' concerns that "unreasonable" corporate expectations are leading to pharmacists making errors in filling prescriptions and failing to comply with safety procedures) (internal quotations omitted).

102. Ellen Gabler, How Chaos at Chain Pharmacies Is Putting Patients at Risk, N.Y. Times, Feb. 1, 2020, at A1 (reporting that corporate policies in some major drug store chains may be causing pharmacists to make errors in filling and dispensing prescription medications).

103. See Kimberly A. Burns \& Alan R. Spies, A Pharmacist's Duty to Warn: Promoting the Acceptance of a Consistent Legal and Professional Standard, 47 DuQ. L. REV. 1, 23-24 (2009) (discussing news reports of pharmacy chains potentially creating an environment where errors are more likely to occur when pharmacists are encouraged to quickly fill a large number of prescriptions in order to meet corporate expectations).

104. Simshaw et al., supra note 88 , at 10-18 (providing an overview of types of robots used in the health care environment).

105. Id.

106. Andrew C. Seger et al., Impact of Robotic Antineoplastic Preparation on Safety, Workflow, and Costs, 8 J. Oncology Prac. 344, 344 (2012).

107. Summerfield et al., supra note 90 , at 80 . 
changing health care landscape. While marketplace competition, ${ }^{108}$ improved quality of care, ${ }^{109}$ increased patient access, ${ }^{110}$ and health care cost saving ${ }^{111}$ are often the focus of merger debates, the impact on pharmacists and the practice of pharmacy is often overlooked. ${ }^{112}$ The CVS-Aetna merger of "healthcare giants,"113 the Cigna-Express Scripts merger, and Amazon's acquisition of PillPack will likely further tip pharmacists closer to federal pharmacist provider status by moving pharmacists closer to providing primary care.

Amazon's almost $\$ 1$ billion acquisition of PillPack, a customizable prescription medication platform, ${ }^{114}$ may make ordering prescription medications online an acceptable-and possibly preferable-alternative to brick-and-mortar pharmacies. ${ }^{115}$ Moreover, this acquisition will likely motivate Amazon to improve supply chain efficiencies, ${ }^{116}$ further increasing pharmacy automation and relieving pharmacists of more mundane tasks.

The CVS-Aetna merger exemplifies the popular effort to change the health care delivery system and increase access to health care services. ${ }^{117}$ One likely outcome of the CVS-Aetna merger ${ }^{118}$ is the ex-

108. Jaime S. King \& Erin C. Fuse Brown, The Anti-Competitive Potential of CrossMarket Mergers in Health Care, 11 St. Louis U. J. Health L. \& Pol'y 43, 44 (2017).

109. Kent Bernard, Taking Quality of Health Care Seriously in Provider Merger Analysis, 11 St. Louis U. J. Health L. \& Pol'y 161, 174 (2017).

110. Melissa Quintana, Measuring Hospital Post-Merger Effects: Developing a Standard for Antitrust Analysis, 21 N.Y.U. J. Legis. \& Pub. PoL'y 957, 984 (2019).

111. Roger D. Blair, Christine Piette Durrance \& D. Daniel Sokol, Hospital Mergers and Economic Efficiency, 91 WASH. L. REV. 1, 62 (2016).

112. See generally John Gitta, Comment, The Impact of Merger \& Acquisitions on Smaller Pharmacy Market Participants and Consumers, 27 Annals Health L. AdVANCE Directive 163, 163 (2018) (providing alternative solutions to improve pharmacy accessibility following the changing pharmacy landscape created by mergers and acquisitions). Consolidation through mergers, however, may also raise questions of pharmacy accessibility particularly in underserved communities. Id. at 174 .

113. United States v. CVS Health Corp., 407 F. Supp. 3d 45, 48 (D.D.C. 2019) (describing CVS and Aetna as "healthcare giants," specifically CVS as "one of the largest companies in the United States" and Aetna as the "nation's third-largest health-insurance company" (internal quotations omitted)).

114. Mollie Levy, Marketing Medicine to Millennials: Preparing Institutions and Regulations for Direct-to-Consumer Healthcare, 55 CAL. W. L. REv. 521, 531 (2019). PillPack delivers prescription medications, dietary supplements, and over-the-counter medications in individualized daily packages, making patient adherence to medications more convenient. Id. at 540.

115. Jim Butschli, Amazon's PillPack Acquisition Could Transform Online Pharmacy Market, HealthCARE PACKaging (July 16, 2018), https://www.healthcarepack aging.com/home/article/13295041/amazons-pillpack-acquisition-could-transform-online-pharmacy-market [https://perma.cc/E7G6-PR4J].

116. Gary Forger, Pharma Races Toward Its Future, Mod. Materials Handling (Dec. 10, 2019), https://www.mmh.com/article/pharma_races_towards_its_future [https://perma.cc/Q7E2-VCEP].

117. Julia Kapchinskiy, The Duality of Provider and Payer in the Current Healthcare Landscape and Related Antitrust Implications, 55 SAN Diego L. Rev. 617, 618 (2018) (discussing the blurred health care lines in the CVS-Aetna merger); Leslie A. Saxon \& Anjali Doshi, Editorial Commentary: Re-Inventing Chronic Disease Manage- 
pansion $^{119}$ of CVS's MinuteClinics, clinical facilities within CVS stores. ${ }^{120}$ Patients visit MinuteClinics seeking treatment for health concerns such as minor cuts, the flu, or strep throat. Patients may choose to visit a MinuteClinic rather than a physician's office because the MinuteClinic is more readily accessible both geographically and temporally, and it may cost them less money. ${ }^{121}$

More significantly, CVS's merger with Aetna is also likely to expand the volume of primary care provided in MinuteClinics (potentially doubling it) ${ }^{122}$ as well as expand the type of primary care by increasing its management of chronic diseases. ${ }^{123}$ With more potential primary care available, patients may gravitate toward MinuteClinics

ment as a Service-Medication Adherence Solutions Are Ground Zero, 29 Trends Cardiovascular Med. 118, 118 (2019).

118. Because of the interrelatedness of pharmacies, insurers, and pharmacy benefit managers, it is notable that in addition to operating its community pharmacy chain and MinuteClinics, CVS also operates Caremark, a pharmacy benefit manager. Off. Pub. Affs., Judge Decides CVS-Aetna Final Judgment Is in the Public Interest and Grants United States' Motion, DeP'T Just. (Sept. 4, 2019), https://www.justice.gov/opa/ $\mathrm{pr} /$ judge-decides-cvs-aetna-final-judgment-public-interest-and-grants-united-statesmotion [https://perma.cc/FGC3-NRQB]. "Three PBMs (CVS Caremark, OptumRx, and Express Scripts) control approximately $75 \%$ of the PBM market . ..." Katherine L. Gudiksen \& Jaime S. King, The Burden of Federalism: Challenges to State Attempts at Controlling Prescription Drug Costs, 39 J. Legal Med. 95, 105-06 (2019). PBMs, which establish and negotiate drug coverage terms between pharmacies and insurers, are basically invisible to the consumer or patient. Kate Cox, Cigna, Express Scripts Receive Final Approval, Close \$67 Billion Deal, CQ Roll CAll, Dec. 21, 2018, at 1, 2018 WL 6719719.

119. Currently, there are approximately 1,100 MinuteClinics located in CVS and Target stores in thirty-three states and the District of Columbia. Now Offering Access to MinuteClinic at No Cost to the Member, Aetna (2019), https:// www.townebenefits.com/media/103536/aetna-minuteclinic-flyer-final.pdf [https:// perma.cc/7FCL-G89S]. Approximately one-ninth of CVS locations currently contain a MinuteClinic. Drew Gerber, CVS Plans Could Change the Face of Health Care, NAT'L J. (Mar. 15, 2018, 8:00 PM), https://www.nationaljournal.com/s/665317/cvsplans-could-change-face-health-care [https://perma.cc/PJL3-PH86]. Some Target stores also have MinuteClinics. Rebekah Williams, Aetna: Now Offering MinuteClinic, Messer Fin. Grp.: Carrier Updates (June 14, 2019), https:// www.messerfinancial.com/insurance-industry-news/carrier-updates/1567-aenta-nowoffering-minuteclinic [https://perma.cc/YA7L-LMT3] (suggesting there is plenty of room for expanding the sheer number of MinuteClinics).

120. Gerber, supra note 119.

121. MinuteClinics charge less than outpatient clinics, urgent care facilities, and emergency departments. Leemore S. Dafny, Perspective, Does CVS-Aetna Spell the End of Business as Usual?, 378 New ENG. J. MED. 593, 593-95 (2018).

122. Testifying at a Congressional subcommittee, CVS Executive Vice President Thomas Moriarty explained CVS's vision of potentially doubling the amount of primary care services provided at MinuteClinics. Gerber, supra note 119.

123. $I d$. 
because they are convenient. ${ }^{124}$ Moreover, patients insured by Aetna may be incentivized to use MinuteClinics and other CVS services. ${ }^{125}$

Although now care at facilities such as MinuteClinics is usually provided by nurse practitioners or physician assistants, ${ }^{126}$ if pharmacists have federal pharmacist provider status and are able to independently bill Medicare, it is likely pharmacists will play a greater role in providing some primary care services. ${ }^{127}$

\section{Transitioning to Value-Based Care}

Spurred in part by PPACA ${ }^{128}$ and the 2015 Medicare Access and CHIP Reauthorization Act ("MACRA"), ${ }^{129}$ fee-for-service payment models are being replaced with value-based reimbursement models. ${ }^{130}$

124. But see id. (reporting that CVS indicates that its primary care aims focus on those patients lacking access to primary care rather than potentially siphoning off patients with established primary care).

125. For example, an Aetna flyer encourages members interested in tobacco cessation and other public health goals to use MinuteClinics to focus on their health goals "right in [their] own neighborhood." A Convenient Way to Focus on Your Health Right in Your Own Neighborhood, Aetna (2013), http://www.usmc-mccs.org/employ/ benefits/documents/aetnacvsminuteclinicflyer.pdf [https://perma.cc/Z8V6-J6U8]. CVS Health is another merger benefit for Aetna. Through CVS Health, Aetna now offers Medicare beneficiaries blood pressure monitoring at home and coverage of fall prevention supplies. Aetna's 2020 Medicare Plans Connect Members with More Personalized Care and Benefits in Their Homes and Communities, CVS Health (Oct. 24, 2019), https://cvshealth.com/newsroom/press-releases/aetnas-2020-medicare-plansconnect-members-with-more-personalized-care [https://perma.cc/23S6-9K88]. CVS Health Chief Executive, Larry Merlo, announced that CVS-Aetna aims to provide coverage for $80 \%$ of Medicare-eligible patients. Bruce Jaspen, CVS' Aetna Targets 4 in 5 Medicare Seniors for Advantage Plans, Forbes (Aug. 8, 2019, 8:00 AM), https:// www.forbes.com/sites/brucejapsen/2019/08/08/cvs-aetna-targets-4-in-5-medicare-seniors-for-advantage-plans/\#8ce5f2614b72 [https://perma.cc/R7SB-NT5W]. This would be an increase from $75 \%$ in 2019. Bruce Jaspen, CVS Profits Jump amid National HealthHub Expansion, Forbes (Aug. 7, 2019, 8:53 AM), https://www.forbes.com/ sites/brucejapsen/2019/08/07/cvs-profits-jump-amid-national-healthhub-expansion/ \#1567cf534a70 [https://perma.cc/CK9G-MB6B]. 2020 marks the first year Medicare Advantage Plans will be offered following the merger, further underscoring the significance of the different pathways for accessing primary care services at CVS stores.

126. Gerber, supra note 119.

127. Only time will tell as to whether CVS-Aetna's large network of brick-andmortar access points to a variety of health care services will provide sufficient protection from online competition from dominant entities such as Amazon. Meyersohn, supra note 55.

128. Patient Protection and Affordable Care Act, Pub. L. No. 111-148, 124 Stat. 119 (2010). Although value-based payment programs began more than a decade before the PPACA was enacted, the PPACA financially incentivizes providers to achieve good patient outcomes at lower costs. Susan Adler Channick, The ACA, Provider Mergers and Hospital Pricing: Experimenting with Smart, Lower-Cost Health Insurance Options, 6 WM. \& MARY PoL'y Rev. 95, 96 (2015).

129. Medicare Access and CHIP Reauthorization Act, Pub. L. No. 114-10, 129 Stat. 87 (2015).

130. E.g., Rick Mayes \& Soleil Shah, MACRA and Medicare's Elusive Quest for Fairness and Value with Physician Payment Policy: Speeding Up the Transition to "Big Med”, 11 St. Louis U. J. Health L. \& Pol'y 235, 236 (2018) (tracing the evolution of Medicare physician payment from the beginning of Medicare through the enact- 
Historically, based on a fee-for-service model, Medicare and other payers paid physicians for each service provided, such as a wellness visit, an x-ray, or a surgery. ${ }^{131}$ Under this model, physicians acting as "rational and selfish economic actors . . . are incentivized to deliver high-volume, high-cost care." ${ }^{32}$ The fee-for-service payment system led the United States to have the most expensive health care system in the world, sometimes with lower quality than other nations. ${ }^{133}$ Gradually, fee-for-service systems are transitioning to value-based systems.

Value-based care strives to better align provider reimbursement with payer and patient incentives. ${ }^{134}$ Thus, rather than being paid based on the number of procedures and services that a provider performs, payment is based on the quality of care provided and cost savings. ${ }^{135}$ Including pharmacists as eligible Medicare providers in a value-based care system will allow pharmacists' expertise to directly contribute to quality of care and cost savings by providing patient services and enhancing interdisciplinary teamwork across the patient continuum of care. ${ }^{136}$

The weight that value-based care adds to the tipping point may depend, in part, on the 2021 presidential administration. For example, although the Trump Administration claimed to support the movement to value-based care, it also emphasized the need to reduce the regulatory burden associated with value-based care, shifting from mandatory to voluntary programs and decreasing any federal oversight, ${ }^{137}$ likely slowing down our transition to value-based care. Transition speed impacts the weight value-based care adds to the tipping point scale; the slower the transition, the less weight. Biden's Administration is likely to increase the speed of our national progress toward value-based care, thereby pushing us closer to the tipping point.

ment of MACRA); Richard J. Zall, Jeff J. Marwil \& Mara A. Wilber, MACRA: Quality-Based Payment and Its Implications for Stakeholders, 35 AM. BANKR. Inst. J. 16, 16 (2016) (explaining the two payment pathways under MACRA: the merit-based incentive payment system ("MIPS") and the alternative payment model ("APM")).

131. Wendy Netter Epstein, Revisiting Incentive-Based Contracts, 17 YALE J. Health Pol'y L. \& Ethics 1, 6-7 (2017).

132. Id.

133. Id.

134. Amy B. Monahan, Value-Based Mandated Health Benefits, 80 U. Colo. L. REV. 127, 128-29 (2009).

135. Anne B. Claiborne, Julia R. Hesse \& Daniel T. Roble, Legal Impediments to Implementing Value-Based Purchasing in Healthcare, 35 AM. J.L. \& MED. 442, 443 (2009).

136. Newman et al., supra note 34, at 996.

137. Elizabeth Tobin-Tyler, Health Justice in the Age of Alternative Facts and Tax Cuts: Value-Based Care, Medicaid Reform, and the Social Determinants of Health, 12 St. Louis U. J. Health L. \& Pol'y 29, 49 (2018). 


\section{Advanced Pharmacy Technicians}

Also driving the need for federal reform are the developing changes to how pharmacy technicians are utilized in pharmacies. As with many of the other changes in the health care system, using pharmacy technicians may enable pharmacists to have a greater role in direct patient care.

Pharmacy technicians are critical pharmacy personnel who perform non-judgmental tasks under the supervision of a licensed pharmacist. ${ }^{138}$ The precise responsibilities of a pharmacy technician are governed by the state laws where the pharmacy technician is working. ${ }^{139}$ Typically, pharmacy technicians prepare and compound medication while advanced pharmacy technicians may take on additional tasks such as obtaining patients' medication histories and working with other advanced pharmacy technicians to dispense medications. ${ }^{140}$

Pharmacies utilize pharmacy technicians to complete limited tasks at a lower cost, which permits pharmacists to focus more on patient care. Delegating more of the prescription-dispensing tasks to pharmacy technicians is one method of increasing time for pharmacists to provide direct patient care services. ${ }^{141}$ Typically, a pharmacist verifies a prescription's accuracy prior to dispensing it to a patient. This verification may also be completed using a tech-check-tech program, in which a qualified pharmacy technician checks the work of another qualified pharmacy technician prior to the drug being dispensed. ${ }^{142}$ While tech-check-tech programs began in hospital and long-term care pharmacies, their use is expanding into community pharmacies. ${ }^{143}$ An Iowa study indicates that a tech-check-tech program in a community pharmacy ${ }^{144}$ increases the time available for pharmacists to provide direct patient care. ${ }^{145}$ In an eight-hour work shift, the study reports that the total number of patient services provided by pharmacists increased from twenty-three to approximately forty-one, ${ }^{146}$ almost doubling the number of patient services. Notably, this study found a

138. See Steven W. Huang, The Omnibus Reconciliation Act of 1990: Redefining Pharmacists' Legal Responsibilities, 25 AM. J.L. \& Med. 417, 420 (1998).

139. Knoer, Eck \& Lucas, supra note 29.

140. $I d$.

141. Michael Andreski et al., The Iowa New Practice Model: Advancing Technician Roles to Increase Pharmacists' Time to Provide Patient Care Services, 58 J. Am. PharMACISTS Ass'N 268, 269 (2018).

142. Id. (explaining that pharmacy technicians must be certified in order to participate in a tech-check-tech program).

143. Id. (describing the results of an eighteen-month pilot project in Iowa community pharmacies in which qualified pharmacy technicians verified a refilled prescription by another qualified pharmacy technician).

144. Id. at 273 (describing the community pharmacies in this study as small chain or independent pharmacies; similar research results may not occur at higher-volume or large chain pharmacies).

145. Id. at 272.

146. Id. 
significant increase in non-reimbursed pharmacist services. ${ }^{147}$ Having more time may enable pharmacists to provide increased direct patient care services, but without commensurate reimbursement, providing additional patient services remains unsustainable.

Pharmacy technicians are now preparing to assume more advanced roles in the pharmacy, including managing robotics and assuming more supervisory roles. As these advanced roles evolve, pharmacists may have more time and energy to function at the top of their licensure-if the law permits them. Combined, automation, mergers, value-based care, and the use of pharmacy technicians, among other changes in the health care system, create the motivation and context for more comprehensive federal action that state efforts cannot provide.

\section{Learning from State and Federal Efforts to Establish Pharmacist Provider Status}

These many changes in our health care landscape ${ }^{148}$ are likely to force the issue of federal pharmacist provider status. State statutes establishing pharmacist provider status are common, but they are not a satisfactory substitute for federal provider status, especially given these external pressures. State statutes and legislative histories, however, illustrate some of the important parameters, such as who can provide what service where, that any federal solution will need to address. Focusing on the West Coast states, this Part analyzes the key elements of state statutory pharmacist provider status that can inform federal law. This Part also examines pharmacist provider status efforts at the federal level because the failure of these efforts, to date, signifies how important the changes in the health care system are in creating a tipping point making federal pharmacist provider status not just possible but probable.

\section{A. State Pharmacist Provider Status Legislation: A Spotlight on the West Coast States' Provider Status Legislation}

California, Oregon, and Washington were among the first states to statutorily establish pharmacist provider status. ${ }^{149}$ As provider status migrated up the coast from California, each state chose different regulatory mechanisms to address the issue of pharmacist provider status.

147. $I d$.

148. See supra Part III.

149. Arizona and West Virginia also enacted pharmacist provider status laws during the same time frame as California, Oregon, and Washington. 2019 State Legislative Wins for Community Pharmacists, NAt'L CMty. Pharmacists Ass'N 1, 4-5 (Jan. 17, 2020), http://www.ncpa.co/pdf/2019-state-legislative-wins-com-pharm.pdf [https:// perma.cc/6RN2-CEKD]. Other states continue to enact and implement pharmacist provider status statutes. For example, Ohio enacted Substitute S.B. 265 in 2019. S.B. 265, 132d Gen. Assemb., Reg. Sess. (Ohio 2018). 
In recognizing pharmacists as health care providers, some states have chosen to simultaneously establish new categories of pharmacists with advanced training or clinical practice. California statutorily recognizes all pharmacists as health care providers, including a new pharmacist category, the Advanced Practice Pharmacist. ${ }^{150}$ In a similar fashion, Oregon adds a new category of clinical pharmacy practitioners $^{151}$ to the types of pharmacists recognized as health care providers. ${ }^{152}$ Washington, however, creates no new category of advanced or clinical pharmacists; all Washington pharmacists are considered providers under the state's "every category of provider" classification. ${ }^{153}$

While a pharmacist may perform any health care service within her scope of practice, the question remains whether the pharmacist is eligible for reimbursement for such service. State statutes typically specify the precise reimbursable services a pharmacist may perform. These services, however, are a subset of a pharmacist's entire scope of practice.

For instance, a California pharmacist's scope of practice includes administering prescribed drug and biological products; providing patient consultations; educating patients regarding drug therapy, disease management, and disease prevention; ordering and interpreting laboratory tests to monitor and manage drug therapies (including controlled substances); furnishing nicotine replacement products; administering vaccines; and providing travel medications and hormonal contraception. ${ }^{154}$ A California Advanced Practice Pharmacist may perform additional services, including assessing patients, referring patients to other providers, and initiating, adjusting, and discontinuing drug therapy. ${ }^{155}$ The only Medicaid-reimbursable ${ }^{156}$ services a California pharmacist may provide, however, are furnishing nicotine replacement products, administering vaccines, and providing travel medications and hormonal contraception. With none of the Advanced Practice Pharmacist services eligible for reimbursement, ${ }^{157}$ California

150. Cal. Bus. \& Prof. Code $\S 4016.5$ (West 2020).

151. Clinical pharmacy practitioners in Oregon engage in a team approach to providing patient care, including post-diagnostic disease state management. OR. REV. Stat. Ann. § 689.005(30) (West, Westlaw through ch. 19 of 2020 2d Spec. Sess.).

152. Or. Rev. Stat. Ann. § 689.005 (Westlaw, current through ch. 19 of 2020 First Spec. Sess.).

153. Other states, such as Ohio, have also opted not to create special categories of pharmacists. See Ohio Rev. Code AnN. § 1751.01 (West 2019).

154. Cal. Bus. \& Prof. Code $\$ 4052$ (West 2020).

155. Cal. Bus. \& Prof. Code $\S 4052.6$ (West 2020).

156. Cal. Welf. \& Inst. Code $\$ 14132.968$ (West 2020). In order to achieve any reimbursement, two bills had to be enacted in California: California Senate Bill 493 (declaring the practice of pharmacy to be a profession), S.B. 493, 2013-2014 Reg. Sess. (Cal. 2013), and California Assembly Bill 1114 (mandating reimbursement at 85\% for certain services), Assemb. B. 1114, 2015-2016 Reg. Sess. (Cal. 2016).

157. If California Senate Bill 1285, introduced in 2018, had passed instead of dying in the Senate, it would have required health care service plans to cover Advanced Practice Pharmacist services. S.B. 1285, 2017-2018 Reg. Sess. (Cal. 2018). 
reimburses pharmacist providers for only a small subset of services within all California pharmacists' scope of practice.

Similar to California's reimbursement scheme, Washington's reimbursement for pharmacist providers applies only to certain pharmacist services. ${ }^{158}$ Washington distinguishes between major medical benefits and drug benefits. ${ }^{159}$ Pharmacist provider status requires reimbursement for services complying with state-mandated health benefits and within a pharmacist's scope of practice. ${ }^{160}$ These services, covered by a patient's major medical benefit, could also be provided by a physician, physician assistant, or advanced registered nurse practitioner. ${ }^{161}$ Drug benefits are not covered by Washington's statute. Unlike California and Washington's reimbursement scheme, Oregon's permits any health care service within a pharmacist's scope of practice to be eligible for reimbursement. ${ }^{162}$ Oregon's statutory scheme, however, permits, rather than requires, public and private insurers to reimburse a pharmacist. ${ }^{163}$

Perhaps most notably, the West Coast states refrained from placing any limitations on where a pharmacist could perform a service as a provider. ${ }^{164}$ In these states, a pharmacist's provider status is not linked to practicing in a specific community, such as an underserved community. ${ }^{165}$

While states granting pharmacists provider status permit pharmacists to bill private insurers ${ }^{166}$ or Medicaid programs, ${ }^{167}$ states lack the jurisdiction to enable pharmacists to bill Medicare.

158. Most Washington State private health plans are required to compensate pharmacists; public plans are not required to reimburse pharmacists. See Thomas K. Hazlet, Tanya E. Karwaki \& Donald F. Downing, Commentary, Pathway to Pharmacist Medical Provider Status in Washington State, 57 J. Am. Pharmacists Ass'N 116, 118 (2017).

159. $I d$.

160. Washington State mandates additional benefits beyond those required by the PPACA. Wash. Rev. Code $§ 48.43 .094$ (2020).

161. Washington's statute does not impact patients' drug benefits, which are distinct from major medical benefits. Hazlet, Karwaki \& Downing, supra note 158, at 116.

162. Or. Rev. Stat. § 414.764 (2020).

163. Id.

164. See, e.g., Assemb. B. 1114, 2015-2016 Reg. Sess. (Cal. 2016); S.B. 493, 2013-2014 Reg. Sess. (Cal. 2013).

165. Compare Assemb. B. 1114, 2015-2016 Reg. Sess. (Cal. 2016), and S.B. 493, 2013-2014 Reg. Sess. (Cal. 2013), with Pharmacy and Medically Underserved Areas Enhancement Act, H.R. 592, 115th Cong. (1st Sess. 2017) (proposing federal legislation allowing pharmacist service provider status but limiting where the services can be provided).

166. E.g., Wash. Rev. Code $\$ 48.43 .094$ (2020).

167. E.g., Cal. Welf. \& Ins. Code $§ 14132.968$ (West 2020). 


\section{B. Federal Pharmacist Provider Status}

Federal policy stakeholders, including administrative agencies and nonprofit organizations, support expanded pharmacist contributions to the U.S. health care system. In 2012, the Centers for Disease Control and Prevention ("CDC") reported that engaging pharmacists in the health care system would improve quality and lower costs. ${ }^{168} \mathrm{~A}$ few years earlier, the U.S. Surgeon General praised a U.S. Public Health Service report recommending pharmacists be recognized as health care providers. ${ }^{169}$ Administrative agencies were not the only entities interested in propelling pharmacists to practice closer to the top of their licensure; at least one influential nonprofit organization providing leadership on health care issues also advocated for increased access to pharmacists. According to the Institute of Medicine's ("IOM") 2000 landmark report, To Err Is Human: Building a Safer Health Care System, hospital pharmacists are an essential resource and should always be available. ${ }^{170}$

As this Subpart illustrates, however, the CDC's and U.S. Surgeon General's support, among others, have failed to lead to the enactment of legislation establishing federal pharmacist provider status. Briefly analyzing the trends of previous unsuccessful federal bills addressing federal pharmacist provider status is useful in better understanding the context of federal pharmacist provider status in our changing health care landscape. Specifically, this history of repeated bill failure, even with progressively narrower bills, demonstrates the significance of Gladwell's Tipping Point, for arguably without reaching this Tipping Point, there is little evidence that federal pharmacist provider status will be established any time soon.

\section{Legislating Federal Pharmacist Provider Status}

More than eight bills addressing Medicare Part B's coverage of pharmacist services have been introduced in Congress. Although the original bill began with a broad concept of pharmacist provider status,

168. Cynthia M. Morrison et al., A Program Guide for Public Health: Partnering with Pharmacists in the Prevention and Control of Chronic Diseases, NAT'L CTR. FOR Chronic Disease Prevention \& Health Promotion 1, 6 (Aug. 2012), https:// www.cdc.gov/grand-rounds/pp/2014/20141021-pdf-pharmacist-role-508.pdf [https:// perma.cc/Z55R-MCJL].

169. See Linehan, supra note 15, at 21. The Office of the Surgeon General is part of the Department of Health and Human Services. Off. of the Surgeon Gene., About the Office of the Surgeon General, U.S. Dep't Health \& Hum. Servs. (May 14, 2019), https://www.hhs.gov/surgeongeneral/about/index.html [https://perma.cc/YBR24AVD].

170. Comm. on Quality of Health Care in Am., Inst. of Med. of the Nat'l Acads., To Err Is Human: Building a Safer Health Care System 194 (Linda T. Kohn, Janet M. Corrigan \& Molla S. Donaldson eds., 2000). IOM has been renamed and is now called the Health and Medicine Division. About the Health and Medicine Division, NAT'L ACADs., https://www.nationalacademies.org/hmd/about [https://perma.cc/9N42-QEPS]. 
subsequent bills narrowed the breadth of pharmacist provider status. Regardless of the approach each bill took regarding pharmacist provider status, these bills all died quickly after being referred to subcommittees.

The first and broadest of these bills, the "Medicare Pharmacist Services Coverage Act of 2001,"171 likely represents pharmacists' ultimate goal, which has been continually modified in subsequent bills. This bill would have facilitated reimbursement for pharmacist services provided to a Medicare beneficiary anywhere in the United States, subject to state law scope-of-practice restrictions. ${ }^{172}$ Over the following few years, limitations were added to subsequent bills in an effort to identify components of a bill capable of gaining traction in Congress. The restrictions targeted the type of patient treated, such as high-risk asthmatic or diabetic patients, ${ }^{173}$ and the clinical skills of the pharmacists. ${ }^{174}$ Yet, even with these limitations, the bills were unable to become law.

The most recent iterations of this federal bill tried a different strategy, allowing a greater number of pharmacists to participate in providing reimbursable pharmacist services, but limiting where these services can be provided. ${ }^{175}$ Under the more recent proposed bills, any pharmacist, licensed and acting within her scope of practice, could be reimbursed and was not required to obtain additional advanced training or any other designation. ${ }^{176}$ The services, however, must be provided in a geographical location with a designated provider shortage or vulnerable population. ${ }^{177}$ The types of locations where pharmacists would have federal provider status are health professional shortage areas, with provider shortages in primary care, dental or mental health care,${ }^{178}$ medically underserved areas or medically underserved popu-

171. Medicare Pharmacist Services Coverage Act of 2001, S. 974, 107th Cong. (1st Sess. 2001).

172. $I d$. at $\S 2(\mathrm{~b})$.

173. Medicare Medication Therapy Management Services Coverage Act of 2002, H.R. 5539, 107th Cong. (2d Sess. 2002) (stating reimbursement would only be available to a "qualified pharmacist" providing services in an "eligible State").

174. Medicare Clinical Pharmacist Practitioner Services Coverage Act of 2004, H.R. 4724, 108th Cong. (2d Sess. 2004) (requiring reimbursing only "clinical pharmacist practitioner[s]" providing services pursuant to a collaborative practice agreement, or State certified, with prescriptive authority, and applied scientific principles to direct patient care).

175. Pharmacy and Medically Underserved Areas Enhancement Act, H.R. 592, 115th Cong. (1st Sess. 2017); H.R. 4190, 113th Cong. (2d Sess. 2014).

176. The services must be otherwise covered if provided by a physician or incident to a physician's service. H.R. $4190 \S 1$ (a)(3)(GG)(i); H.R. $592 \S 2(\mathrm{a})(3)(\mathrm{HH})(\mathrm{i})$.

177. H.R. $592 \S 2(a)(3)(H H)($ iii); H.R. $4190 \S 1$ (a)(3)(GG)(iii).

178. Health Res. \& Servs. Admin., Health Professional Shortage Areas (HPSAs), BUREAU HEALTH WORKFORCE, https://bhw.hrsa.gov/shortage-designation/hpsas (May 2020) [https://perma.cc/FM73-6ABX]. 
lations, with too few primary care providers, high infant mortality, or a high elderly population. ${ }^{179}$

\section{Federal Administrative Agency Rulemaking}

In addition to the possibility of legislatively creating federal pharmacist provider status, the same thing could be accomplished through federal administrative agency rulemaking. Seema Verma, the Administrator of the Centers for Medicare and Medicaid ("CMS"), recently suggested that the Trump Administration may consider granting pharmacists federal provider status through administrative rulemaking. ${ }^{180}$ Verma's comments build off of President Trump's Executive Order on Protecting and Improving Medicare for Our Nation's Seniors. ${ }^{181}$ According to this executive order:

[T] he Secretary shall propose reforms to the Medicare program to enable providers to spend more time with patients by:

(a) proposing a regulation that would eliminate burdensome regulatory billing requirements, conditions of participation, supervision requirements, benefit definitions, and all other licensure requirements of the Medicare program that are more stringent than applicable Federal or State laws require and that limit professionals from practicing at the top of their profession;

(b) proposing a regulation that would ensure appropriate reimbursement by Medicare for time spent with patients by both primary and specialist health providers practicing in all types of health professions; and

(c) conducting a comprehensive review of regulatory policies that create disparities in reimbursement between physicians and nonphysician practitioners and proposing a regulation that would, to the extent allowed by law, ensure that items and services provided by clinicians, including physicians, physician assistants, and nurse practitioners, are appropriately reimbursed in accordance with the work performed rather than the clinician's occupation. ${ }^{182}$

A regulation proposed under this executive order could establish federal pharmacist provider status by permitting pharmacists to practice at the top of their licensure or to the fullest extent of their education and training as the law permits. It could also remove the Medicare billing barrier for pharmacists and ensure appropriate reim-

179. H.R. 4190 § 1(a)(3)(GG)(iii); H.R. $592 \S 2(\mathrm{a})(3)(\mathrm{HH})(\mathrm{iii})$.

180. Michelle M. Stein, Verma Hints Pharmacists May Be Considered Providers Under Medicare EO, Inside Health Pol'y (Oct. 30, 2019, 12:44 PM), https://insidehealthpolicy.com/daily-news/verma-hints-pharmacists-may-be-considered-providers-under-medicare-eo [https://perma.cc/KH89-QJ5B].

181. Protecting and Improving Medicare for Our Nation's Seniors, 84 Fed. Reg. 53573, 53573 (Oct. 8, 2019).

182. Id. at 53574 . 
bursement by Medicare, likely at $85 \%$ of the physician fee schedule, for the time pharmacists spend providing patient services. It is possible, however, that the Trump Administration's focus remained on other policy issues, such as reducing drug costs, as opposed to pharmacist provider status, particularly in an election year. It is also possible that internal conflict in the Administration was undermining any policy agenda. ${ }^{183}$

\section{Preparing for a Federal Solution to Pharmacist Provider Status}

Given the transformations occurring in the health care system, it is foreseeable that pharmacists will achieve federal provider status. The real question is when and how. It could occur slowly after the state laboratories have had time to complete their experiments with state pharmacist provider status. If more states follow California's example of taking a two-step, multi-year approach to pharmacist provider status with reimbursement, this timeline will stretch out even longer. ${ }^{184}$ More likely, as this Article asserts, federal pharmacist provider status will happen sooner, driven in large part by our health care system's changes such as increased automation and health care mergers. ${ }^{185}$

To date, federal pharmacist provider status has not been achieved because it is typically framed by stakeholders, particularly providers, as a scope-of-practice and payment issue. This type of framing places federal pharmacist provider status squarely in the turf war category, likely contributing to policymakers' reluctance to take up this issue. More significantly, it ignores the larger health care system changes.

Federal pharmacist provider status may happen either through federal legislation or by federal agency administrative rulemaking. ${ }^{186} \mathrm{~A}$ statutory fix would be preferable since it is less subject to the pendulum swings of different administrations; while a federal rule would achieve the same goal, it might not be as stable. Regardless of whether the solution occurs by statute or rule, this Part analyzes the three key issues that should be addressed by any federal solution: which pharmacists can perform what health care services, what boundaries may

183. Yasmeen Abutaleb et al., Trump Health Promises Thwarted by Feuding Aides, Shifting Orders, WAsH. Post (Dec. 11, 2019), https://www.washingtonpost.com/ health/trump-health-promises-thwarted-by-feuding-aides-shifting-orders/2019/12/11/ 7bf4f3e4-1c3b-11ea-87f7-f2e91143c60d_story.html, [https://perma.cc/3UBU-NJZD].

184. Three years after enacting S.B. 493, the California Legislature passed Assemb. B. 1114 mandating reimbursement for pharmacists providing limited health care services at $85 \%$ of the Medi-Cal physician fee schedule for certain services, including furnishing self-administered hormonal contraception, nicotine replacement products, travel medicines, naloxone, and vaccines. Liesl D. Reyes et al., Community Pharmacists' Motivation and Barriers to Providing and Billing Patient Care Services, 8 PHARMACY 145, 146 (2020).

185. See supra Part III.

186. See supra Part IV. 
be placed on pharmacists providing direct patient care, and how to clarify pharmacists' reimbursement. Finally, this Part examines the barriers to a federal solution and proposes a way forward.

\section{A. Who Can Perform What Services Where?}

Identifying which health care professional can provide what services where while eligible for reimbursement is the crux of provider status. In establishing federal pharmacist provider status, federal policymakers will need to determine which pharmacists can perform what services where in the United States. Careful consideration of the states' experiences ${ }^{187}$ answering the same questions at the state level, in addition to drawing from previously introduced federal bills, is helpful in resolving these challenging questions at the federal level.

While some states, including California and Oregon, create new pharmacist categories such as Advanced Practice Pharmacists ${ }^{188}$ or clinical pharmacy practitioners ${ }^{189}$ as part of establishing state pharmacist provider status, other states, including Washington and Ohio, do not create any special categories of pharmacists. Creating new pharmacist categories has not proven particularly useful for pharmacists in seeking reimbursement. In California, none of the Advanced Practice Pharmacist services are eligible for reimbursement, ${ }^{190}$ leaving little incentive for pharmacists to undertake the required training. ${ }^{191}$ At the federal level, policymakers should make provider status open to all pharmacists without additional restrictions while creating a system to verify a pharmacist's ability to provide certain health care services. ${ }^{192}$ Even with education and advanced training, it is likely that Medicare, as a federal payer, as well as any private or state payers that follow Medicare's reimbursement example, will require verification of pharmacists' capabilities prior to permitting them to independently bill for their services. This verification may be accomplished using pharmacist credentialing and privileging, a similar method for determining the ability and competency of other health care providers. ${ }^{193}$ In fact, in

187. $I d$.

188. Cal. Bus. \& Prof. Code $§ 4016.5$ (West, Westlaw through Ch. 372 of 2020 Reg. Sess.).

189. Or. Rev. Stat. Ann. § 689.005 (West, Westlaw through 2020 Reg. Sess. of 80th Legis. Assemb.).

190. If California S.B. 1285, introduced in 2018, had passed, it would have required health care service plans to cover Advanced Practice Pharmacist services. S.B. 1285 died in the Senate. S.B. 1285, 2017-2018 Reg. Sess. (Cal. 2018).

191. As of 2017, there were 130 Advanced Practice Pharmacists in California. FAQs, Cal. Pharmacists Ass'N, http://appharmacist.com/faqs/ [https://perma.cc/ TK5A-2TN9].

192. Lynette Bradley-Baker, Which Comes First_Credentialing and Privileging in Pharmacy or Pharmacist Provider Status?, 78 Am. J. Pharm. Educ. 1, 1 (2014).

193. Id. 
some states with pharmacist provider status, credentialing and privileging are part of the legislation's implementation process. ${ }^{194}$

Previous federal bills already indicate a feasible approach to what services a pharmacist may perform as a provider for Medicare purposes. Under the federal bills introduced in 2014 and 2017, a pharmacist must be licensed and acting within her scope of practice. ${ }^{195}$ Additionally, the services must be otherwise covered if provided by a physician or incident to a physician's service. ${ }^{196}$ This approach, while perhaps appearing simplistic at first glance, is appropriate because it covers the most significant boundaries on a pharmacist's services. Licensure and scope of practice place necessary restrictions on the pharmacist while leaving the covered services as broad as possible by linking the services a physician may provide.

Federal bills restricting pharmacist federal provider status to areas with the greatest need for health care services, including health professional shortage areas or medically underserved areas, inherently categorize pharmacists as physician extenders, helping alleviate a physician workforce shortage. This is certainly one viable role for pharmacists in our health care system. While it restricts the number of pharmacists eligible to participate based on geography, further legislation could expand federal provider status to the entire United States, similar to how the nursing profession achieved its federal provider status. ${ }^{197}$ But, as this Article argues, federal pharmacist provider status will not be primarily driven by workforce shortages. Thus, the better solution is to follow the states' lead and not limit where a pharmacist can perform services as a provider.

\section{B. Placing Boundaries on Pharmacists' Direct Patient Care}

The potential expansion of primary care through facilities such as MinuteClinics positions pharmacists to take on some functions of a primary care provider, like pharmacists in other countries. ${ }^{198}$ Moreover, as automation in prescription dispensing increases ${ }^{199}$ and advanced pharmacy technicians are permitted to take on additional responsibilities, further relieving pharmacists of many of the more technical tasks involved in pharmacy practice, pharmacists will have

194. See S.B. 5557, 64th Leg., Reg. Sess. (Wash. 2015); Hazlet, Karwaki \& Downing, supra note 158 , at 118 .

195. H.R. 4190, 113th Cong. §1(a)(3)(GG)(i) (2014); H.R. 592, 115th Cong. $\S 2(\mathrm{a})(3)(\mathrm{HH})(\mathrm{i})(2017)$.

196. H.R. $4190 \S 1(\mathrm{a})(3)(\mathrm{GG})(\mathrm{ii}) ;$ H.R. $592 \S 2(\mathrm{a})(3)(\mathrm{HH})(\mathrm{ii})$.

197. Nurses were originally granted provider status in rural areas. See Linehan, supra note 15 , at 23 .

198. Gerber, supra note 119.

199. See Jean Spinks et al., Commentary, Disruptive Innovation in Community Pharmacy - Impact of Automation on the Pharmacist Workforce, 13 RscH. Soc. \& Admin. Pharmacy 394, 395 (2017) (evaluating automated dispensing systems and their impact on the pharmacist workforce). 
more time to devote to providing direct patient care. ${ }^{200}$ Dispensing prescription medications has been a large component of pharmacy practice, but it does not represent the expanded skill set of contemporary pharmacists. Pharmacists earn a Doctor of Pharmacy degree 201 often followed by advanced training through residencies, ${ }^{202}$ fellowships, ${ }^{203}$ and board certifications. ${ }^{204}$ Pharmacists' education and training have prompted recognition of pharmacists' medication expertise as "exceed[ing] any other health care provider's." 05 Some of the clinical services pharmacists may perform include managing chronic diseases, preventing disease, coordinating transitions from inpatient to outpatient care, and monitoring diseases. ${ }^{206}$ From a health policy perspective, it behooves us to encourage pharmacists to provide direct patient care where their medication skills and clinical capabilities may improve patient care outcomes but leaves unanswered the more challenging question of how to regulate pharmacists' provision of direct patient care.

Policymakers could institute a connection between medication therapy and related direct patient care. Drug therapy is a significant part of our approach to health care with almost $75 \%$ of all outpatient physician visits including some form of drug therapy. ${ }^{207}$ Along with the increased use of pharmaceuticals comes an increased risk of potentially avoidable patient harms caused by medication therapies. ${ }^{208} \mathrm{An}$ estimated 275,689 people in the United States die each year because of drug-therapy-related problems. ${ }^{209}$ According to the American Pharmacists Association, more than 1.5 million preventable medica-

200. See Carmen Guadalupe Rodriguez-Gonzalez et al., Robotic Dispensing Improves Patient Safety, Inventory Management, and Staff Satisfaction in an Outpatient Hospital Pharmacy, 25 J. Evaluation Clinical Prac. 28, 28 (2019) (describing how robotic dispensing systems permit pharmacists to spend more time with patients).

201. Yang-Yi Lin, Evolution of Pharm D Education and Patient Service in the USA, 4 J. Experimental \& Clinical Med. (Special Issue) 227, 228 (2012). The Doctor of Pharmacy (PharmD) has been the entry-level degree since 2000. Knoer, Eck \& Lucas, supra note 29, at 33.

202. Knoer, Eck \& Lucas, supra note 29, at 33 (explaining Post-Graduate Year One residencies designed to enhance medication therapy skills and Post-Graduate Year Two residencies designed to focus on a specific pharmacy practice area such as oncology or pediatrics).

203. Id. at 34 (noting that there are fewer fellowship opportunities than residency programs and that fellowships are designed to prepare the fellow for independent research).

204. Id. (commenting that board certification is often required, or at least preferred, in advanced pharmacy practice settings).

205. Jon C. Schommer et al., Pharmacist Contributions to the U.S. Health Care System, 1 Innovations Pharmacy 1, 2 (2010).

206. Newman et al., supra note 37 , at 1156, 1160-62.

207. Watanabe, McInnis \& Hirsch, supra note 6, at 829.

208. Id.

209. Id. at 832 . 
tion-related adverse events occur annually. ${ }^{210}$ If pharmacists participate more directly in patient care, this number will likely decrease. While individually consulting with patients, pharmacists are often able to "identify drug therapy problems, recommend cost saving alternatives, and alert the medical team to patient barriers to care." ${ }^{211}$ Ideally, technological innovations and other changes should facilitate improved patient-pharmacist relationships and better patient medication therapy outcomes. ${ }^{212}$

\section{Resolving Reimbursement}

The only way to achieve uniform eligibility for reimbursement from the most important federal payer, Medicare, is to establish federal pharmacist provider status. CVS's lobbying of Capitol Hill for federal pharmacist provider status ${ }^{213}$ illustrates the importance of independent pharmacist billing of Medicare. Once Medicare sets the reimbursement standard for pharmacists, other payers, including state payers and private insurers, will likely follow Medicare's lead. ${ }^{214} \mathrm{Al}$ though federal policymakers must address pharmacists' reimbursement, they should not necessarily follow the path of least resistance and establish pharmacists' provider reimbursement at $85 \%$ of the physician fee schedule, similar to nurse practitioners and physician assistants. Further research may help determine if mimicking other providers' reimbursement schedules fully accounts for any difference in provider training, education, and clinical capabilities.

Pharmacists may facilitate the provision of value-based and costeffective health care services by improving medication adherence and measuring patient outcomes. Pharmacists may also help physicians achieve their quality measures in a value-based care system. ${ }^{215}$ While pharmacists may now be reimbursed for aiding physicians with meeting their quality targets by billing incident-to a physician, ${ }^{216}$ billing under a collaborative practice agreement, ${ }^{217}$ or via a separate contract directly linking reimbursement to meeting the quality measures, ${ }^{218}$

210. Advancing the Value of MTM, Am. Pharmacists Ass'n, https://portal.pharmacist.com/advancing-value-mtm [https://perma.cc/D753-SBXN].

211. Nathan Hemberg et al., Commentary, Innovative Community Pharmacy Practice Models in North Carolina, 78 N.C. MeD. J. 198, 198 (2017) (explaining the evolving role of a community pharmacist at the Carolina Apothecary).

212. Muhammad Umair Khan et al., Could an Automated Machine Replace the Pharmacist?, 13 Rsch. Soc. \& Admin. Pharmacy 399, 399 (2017).

213. Gerber, supra note 119.

214. Linehan, supra note 15, at 20.

215. Raechel Moore et al., Letters, Enhancing Pharmacy Services in a Primary Care Setting to Help Providers Improve Quality Performance Measures, 76 Am. J. HealthSys. PharmaCy 1460, 1460 (2019) (explaining that pharmacists may impact approximately 300 different quality measures).

216. Id.

217. Id.

218. Id. 
none of these billing alternatives are as simple and effective as permitting pharmacists to bill directly as a provider.

\section{Existing Barriers to a Federal Solution}

Although many payers may decide to follow Medicare regarding any change to pharmacists' eligibility to seek reimbursement, state legislation may still be necessary to align pharmacist services with state payer reimbursement. Federal action is needed first, however, to establish a uniform policy across the nation for the most significant federal payer, Medicare. Once that is accomplished, it is likely that states will quickly follow suit and pharmacists will qualify for reimbursement commensurate with the services they provide to patients.

Scope of practice conflicts highlight the business aspect of the health care system. ${ }^{219}$ Providers generally want to expand their own scope of practice while limiting other providers' scope of practice because scope of practice is closely linked to provider payment. A health care provider's scope of practice refers to the statutorily defined activities or areas in which a particular provider is authorized to practice. ${ }^{220}$ Physicians have the broadest scope of practice, while other providers have more narrow scopes of practice. ${ }^{221}$ Because many different providers' scopes of practice are not unique and may overlap with other providers' scopes of practices creating a conflict, scope of practice has been referred to as "a regulatory train wreck in the making." 222

The American health care system, long deferring to physician expertise as evidenced by our laws and health care practice norms, ${ }^{223}$ may benefit from encouraging non-physician health care practitioners to practice at the top of their licensure. ${ }^{224}$ Yet, tensions among differ-

219. Health care, once considered an art, is now practiced as a business. Daniel R. Santola, The Changing World of Medicine and the Law that Protects Its Patients, AsPATORE, May 2012, at *8, 2012 WL 1189457.

220. Barbara J. Safriet, Closing the Gap Between Can and May in Health-Care Providers' Scopes of Practice: A Primer for Policymakers, 19 Yale J. on Regul. 301, 303-04 (2002) (summarizing the conflicting stakeholder perspectives that legislators will confront whenever addressing a scope of practice issue and noting that legislators may not be well prepared to determine the boundaries of different types of providers).

221. Id. at 316 (asserting that "[f] or historical, rather than logical, reasons, physicians enjoy an overly expansive scope of practice, while all other [providers] are overly restricted[]").

222. Id. at $310-11$.

223. William M. Sage, Assembled Products: The Key to More Effective Competition and Antitrust Oversight in Health Care, 101 Cornell L. Rev. 609, 623 (2016) (explaining how American health care has been directed by physicians in a medicalist model for more than a century).

224. See Matthew Murawski et al., Advanced-Practice Pharmacists: Practice Characteristics and Reimbursement of Pharmacists Certified for Collaborative Clinical Practice in New Mexico and North Carolina, 68 Am. J. Health-Sys. Pharmacy 2341, 2342 (2011) (indicating that pharmacists with advanced-practice designations have 
ent provider groups typically increase whenever one type of provider, such as pharmacists, strives to gain something the other providers already have, such as federal provider status. ${ }^{225}$

It is foreseeable that powerful stakeholders such as physician and nursing organizations may, at first, be against federal pharmacist provider status because of the threat to their reimbursement pathways. For instance, it is forecast that between 2016 and 2030 the number of advanced practice nurses will grow $6.8 \%$ each year, far exceeding the increases forecast for physicians, $1.1 \%$, and physician assistants, $4.3 \% .{ }^{226}$ If this forecast proves accurate, the health system will have many more advanced practice nurses, at least some of whom may strive to prevent pharmacists from further entering into primary care. Yet as the states' success in achieving pharmacist provider status demonstrates, pharmacy collaboration across professional boundaries may win the support —or at least neutrality—of such stakeholders, permitting controversial provider status bills to become law. ${ }^{227}$

In California, the California Medical Association ("CMA") was crucial to passing California's pharmacist provider status bill, SB 493. ${ }^{228}$ With supporters asserting the bill would permit Californians to access high quality care from pharmacists, reduce the costs and strain on California's health care system, and expand team-based care from hospitals to community settings, ${ }^{229}$ opponents argued that the bill put patients at risk. ${ }^{230}$ One opponent, the California Academy of Eye Physicians and Surgeons, alleged that the bill suggested a "two-tiered system where those who are less well-off make do with less trained providers while those with greater resources (i.e. money) go wherever they want." 231 After demanding amendments to the bill and requiring closer collaboration with primary care providers or diagnosing prescribers, CMA adopted a neutral position toward the bill. Once CMA took a neutral stance, organized opposition to the bill ended, and the bill was enacted. ${ }^{232}$

more prescriptive privileges than pharmacists without advanced-practice designations).

225. Keely, supra note 27, at 84 .

226. David I. Auerbach, Peter I. Buerhaus \& Douglas O. Staiger, Implications of the Rapid Growth of the Nurse Practitioner Workforce in the US, 39 Health Affs. 273, 273 (2020).

227. See B. Joseph Guglielmo \& Sean D. Sullivan, Pharmacists as Health Care Providers: Lessons from California and Washington, 1 J. Am. Coll. Clinical PharMACY 39, 40 (2018).

228. Id.

229. See Pharmacy Practice: Hearing on S.B. 493 Before the S. Bus. \& Profs. Comm., 2013-2014 Leg., Reg. Sess. (Cal. 2013) (statement of Dr. Ryan Gates, Senior Clinical Pharmacist at Kern Medical Center, that this bill would permit physicians to delegate "tedious tasks" to pharmacists).

230. California Bill Analysis, S.B. 493, 2013-2014 Reg. Sess. (Cal. 2013).

231. Id.

232. CMA never changed its opposition to the optometrist and nurse practitioner bills. Guglielmo \& Sullivan, supra note 227, at 40. The California Hospital Association 
Oregon's pharmacist provider status bill also encountered resistance from the Oregon Medical Association and Nurses Association, ${ }^{233}$ as well as the Pharmaceutical Research and Manufacturers of America ("PhRMA"). ${ }^{234}$ Oregon's major health care providers, Legacy Health and Kaiser Permanente Northwest, supported the bill, viewing pharmacists as essential health care team members facilitating access to quality health care. ${ }^{235}$ While this support was helpful in the bill's passage, some of the bill's opposition may have dissipated after realizing that permissive reimbursement is a limited threat, as insurers are unlikely to voluntarily reimburse. ${ }^{236}$

Washington's experience also highlights the significance of collaborating across professional boundaries. Washington avoided strong opposition from other providers such as physicians partly because pharmacy advocates worked with the Washington State Medical Association ("WSMA") to ensure that WSMA remained neutral towards the bill. ${ }^{237}$

While pharmacists may want increased autonomy and an expanded scope of practice, ${ }^{238}$ it is important to understand that the primary question of whether pharmacists should be granted federal provider status does not depend on pharmacists achieving either of these goals. Health care associations, such as the American Medical Association, that may be opposed to increasing pharmacists' scope of practice to include prescriptive authority ${ }^{239}$ may be neutral on pharmacist pro-

supported all three of these bills. Key State Issues, CAL. Hosp. Ass'N 1, 6 (Aug. 29, 2013) http://www.calhospital.org/sites/main/files/file-attachments/cha_key_state_issues_8-29-13.pdf [https://perma.cc/BCB4-BC4Q].

233. Loren Bonner, Oregon Enacts Pharmacist Provider Status Law, 21 PhARMACyTODAy 70, 70 (2015).

234. Pharm. Rsch. \& Mfrs. Am., Statement of Opposition for Or. H.B. 2028, S. $362-$ 72960, Reg. Sess. (2015) (opposing the bill because pharmacists are not trained to provide direct patient care).

235. Legacy Health, Legacy Health Support H.B. 2028, S. 362-65708, Reg. Sess. (Or. 2015); Kaiser Found. Health Plan Nw., Support for H.B. 2028, Reg. Sess. (Or. 2015).

236. See Loren Bonner, Pharmacist Provider Status Now Law in Oregon, APHA (June 18, 2015), https://www.pharmacist.com/article/pharmacist-provider-status-nowlaw-oregon [https://perma.cc/84V2-RHA3].

237. Loren Bonner, Washington State Law: Pharmacists Now Providers in Private Health Plans, APHA (May 12, 2015), https://www.pharmacist.com/article/washingtonstate-law-pharmacists-now-providers-private-health-plans-0 [https://perma.cc/Y6L5JTXZ].

238. Linehan, supra note 15 , at 20 (describing provider status as the "linchpin" of a larger pharmacist movement to increase pharmacists' role in our health care delivery system). See also Leighanne Root, Closing the Primary Gap: Is Pharmacist Prescriptive Authority the Answer?, 23 Annals Health L. 66, 73 (2013) (advocating for state legislatures to grant pharmacist prescriptive authority); Alex J. Adams \& Krystalyn K. Weaver, The Continuum of Pharmacist Prescriptive Authority, 50 Annals PhARMACOTHERAPY 778, 778 (2016) (creating a framework for characterizing existing state models of pharmacist prescriptive authority).

239. Letter from the Am. Medical Ass'n opposing Idaho H.B. 182 to the Hon. Brad Little, Governor of Idaho (Mar. 21, 2019) https://searchlf.ama-assn.org/undefined/ 
vider status only altering reimbursement eligibility for pharmacists, not changing pharmacists' scope of practice.

Engaging in "turf wars," 240 or insisting that each provider type "stay in [its] own lane," ${ }^{241}$ may be a valid stance from a provider's perspective, but how policymakers regulate various providers remains a health policy issue. The question is not simply, "Will pharmacists stay within their existing practice boundaries?" but, "Should our health care system encourage pharmacists to help fill a health care gap?"242 This gap filling could include checking on your health status while at your community pharmacy, ${ }^{243}$ or via a pharmacy app ${ }^{244}$ or by using telepharmacy. ${ }^{245}$ Such pharmacist actions need not replace your visits to your physician or other prescriber but complement those visits. Infighting among provider groups is so entrenched in providers' responses and behaviors that it may be necessary for legislators and regulators to temper the conflicts. ${ }^{246}$

The professional responsibilities of physicians, nurse practitioners, physician assistants, pharmacists, and potentially other health care professionals will continue to overlap. Health care providers conducting overlapping services may benefit patients and allow providers to act as "[her] brother's keeper." 247 Working collaboratively, each health care provider can focus on delivering high-quality patient care without expending unnecessary energy waging "turf" battles. ${ }^{248}$ For

documentDownload?uri=\%2Funstructured\%2Fbinary\%2Fletter\%2FLETTERS

\%2F2019-3-21-Letter-in-opposition-to-ID-HB-182-FINAL.pdf [https://perma.cc/ XZ8U-RR26].

240. See Christopher Ogolla, Litigating Hypocrisy: Turf Wars Between Health Care Professionals Regarding Diagnosis, Evaluation, and Treatment, 50 U. Tol. L. ReV. 67, 69-70 (2018) (providing a thorough explanation of turf wars).

241. Comment made to Author by nurse attorney; Symposium Feb. 7, 2020.

242. See Root, supra note 238 , at 71 (detailing how pharmacists may help close the primary care gap by increasing patient adherence to medication therapies and decreasing unnecessary primary care visits to physicians for minor ailments).

243. See Lydia Ramsey Pflanzer, A Health Insurance Startup in North Carolina Is Betting on Pharmacists in an Entirely New Approach to a \$327 Billion Market, Bus. INSIDER (May 1, 2019, 12:00 PM), https://www.businessinsider.com/troy-medicare-advantage-will-pay-pharmacists-to-keep-elderly-members-healthy-2019-4? IR =t [https:// perma.cc/G23Y-WSS2].

244. See Meghan Ross, Gadget Guide: Spark Health App Empowers Pharmacists, Pharmacy Times (Nov. 17, 2015, 2:17 AM), https://www.pharmacytimes.com/publica tions/career/2015/PharmacyCareers_November2015/gadget-guide-spark-health-appempowers-pharmacists [https://perma.cc/56GD-6JVD].

245. Almeta E. Cooper \& Sidney S. Welch, All That Is Mobile: Impact on Your Health Law Practice, 2015 Am. Health L. Ass'n Seminar Papers 1, 5-6 (2015).

246. Safriet, supra note 220, at 323 (highlighting how legislator and regulator involvement in resolving conflict between different provider groups is necessary if the goal of protecting the public "is to be anything more than a gossamer-thin disguise for professional self-interest embedded in law").

247. Riff v. Morgan Pharmacy, 508 A.2d 1247, 1253 (Pa. Super. Ct. 1986) (describing the limited duty physicians, pharmacists, anesthesiologists, nurses, and support staff have regarding acts and omissions).

248. See Keely, supra note 27 , at 84 . 
instance, physicians can maintain medical expertise and focus on patient diagnosis and treatment, while pharmacists can spend time with patients, educating, counseling, and motivating them to adhere to their medication therapy. Therefore, pharmacists can help physicians focus on other, non-drug therapy patient health issues during their patient visits. ${ }^{249}$

The mere fact that other providers will be impacted is not a reason to deprive pharmacists of federal provider status. Rather, the impacts highlight the need for policymakers and stakeholders to consider, and potentially address, scope of practice issues in any legislative or rulemaking solution.

\section{CONCLUSION}

We have not yet reached the tipping point for federal pharmacist provider status, but we are certainly close. By definition, a tipping point causes a quick and dramatic change ${ }^{250}$; in this case, the change would be establishing pharmacists as eligible for Medicare reimbursement. Legislators and regulators should proactively prepare for this tipping point to reach Congress and CMS. Careful consideration of any boundaries on pharmacists' services, particularly regarding any direct patient care, reimbursement levels, and other health care providers' concerns, may yield a federal solution capable of reaping the benefits of federal pharmacist provider status without accentuating any risks.

249. See Maria Castellucci, Is There a Pharmacist in the House? Outpatient Settings Need More Pharmacists but Lack of Reimbursement Makes That a Tough Sell, 49 Mod. Healthcare 36, 37 (2019) (noting that pharmacist visits with patients may last an hour while physician visits are often limited to twenty minutes per patient).

250. Specifically, Gladwell posits that each "Tipping Point" is marked by three characteristics: contagiousness, many little causes contributing to a large effect, and change occurring quickly not gradually. GLADWELL, supra note 75, at 9. 